\title{
ORDEN DE LOS APELLIDOS: AUTONOMÍA PRIVADA, INTERÉS SUPERIOR DEL MENOR Y NO DISCRIMINACIÓN POR RAZÓN DE SEXO
}

Order of surnames: private autonomy, best interests of the child and non-discrimination based on sex

\author{
M. ${ }^{a}$ SUSANA QUICIOS MOLINA \\ Universidad Autónoma de Madrid
}

susana.quicios@uam.es

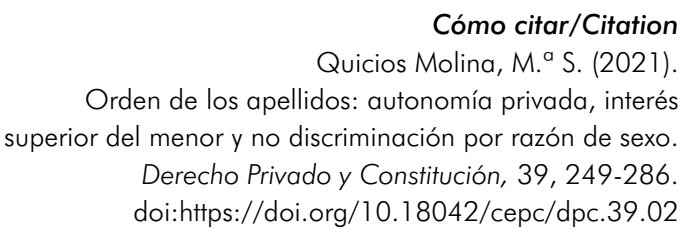

(Recepción: 01/10/2021; aceptación tras revisión:20/10/2021; publicación: 10/12/2021)

\section{Resumen}

La imposición del apellido materno y del apellido paterno a los hijos se ha convertido en una cuestión compleja cuando el legislador ha entendido que la preferencia del apellido paterno es una opción discriminatoria para la mujer. Las sucesivas reformas de nuestro ordenamiento, en 1981, 1999 y 2011, han recurrido a la autonomía privada y al interés superior del menor para resolver el problema, pero la excesiva vacatio legis de la Ley del Registro Civil de 22 de julio de 2011 ha propiciado que los tribunales de instancia siguieran resolviendo las controversias entre los progenitores con arreglo a una norma reglamentaria, poco cuestionada, pero probablemente ilegal. El Tribunal Supremo, sin embargo, recurre al interés superior del menor desde 2015 para priorizar el apellido materno cuando se determina de manera sobrevenida la paternidad. El Tribunal Constitucional no ha sido suficientemente concluyente en sus sentencias, y no se ha pronunciado expresamente sobre la vulneración del principio de no discriminación. El fallo de su Sentencia de 14 de diciembre de 2020 conduce 
a la búsqueda del interés del menor por encima de la voluntad de los progenitores, expresada en la demanda y la contestación.

El Tribunal Europeo de Derechos Humanos, en su reciente Sentencia de 26 de octubre de 2021 (caso León Madrid contra España), ha considerado discriminatoria la regulación española que anteponía el apellido paterno a falta de acuerdo.

\section{Palabras claves}

Apellidos; discriminación por razón de sexo; interés superior del menor; autonomía privada.

\section{Abstract}

The imposition of the maternal surname and the paternal surname on children has become a complex issue when the legislator has understood that the preference of the paternal surname is a discriminatory option for women. The successive reforms of our legal system, in 1981, 1999 and 2011, have resorted to private autonomy and the best interests of the minor to resolve the problem, but the excessive vacatio legis of the Civil Registry Act of 22 July 2011 has led the courts of instance to continue resolving disputes between parents under a regulatory rule, little questioned, but probably illegal. The Supreme Court, however, appeals to the best interests of the minor since 2015 to prioritize the maternal surname when paternity is determined in a supervening manner. The Constitutional Court has not been sufficiently conclusive in its rulings, and has not expressly ruled on the violation of the principle of non-discrimination. The ruling of its Judgment of December 14, 2020 leads to the search for the interest of the minor above the will of the parents, expressed in the claim and the answer.

The European Court of Human Rights, in its recent Judgment of 26 October 2021 (León Madrid v. Spain), has considered discriminatory the Spanish regulation that put the paternal surname first in the absence of agreement.

\section{Keywords}

Surnames; discrimination based on sex; best interests of the child; private autonomy. 


\section{SUMARIO}

I. PLANTEAMIENTO Y OBJETIVO. II. PRIUS: EL DERECHO AL NOMBRE COMO DERECHO DE LA PERSONALIDAD. III. DE DÓNDE VENIMOS. IV. HITOS LEGALES QUE BUSCAN SUPERAR LA HISTÓRICA PREVALENCIA DEL APELLIDO PATERNO: 1. Las reformas de 1981, 1999 y 2011. 2. La anómala situación jurídica desde el 22 de julio de 2011 hasta el 30 de junio de 2017. 3. Régimen legal vigente desde el 30 de junio de 2017. V. EVOLUCIÓN DE LA DOCTRINA CONSTITUCIONAL Y DE LA JURISPRUDENCIA. VI. DOCTRINA RECIENTE DE LA DIRECCIÓN GENERAL DE SEGURIDAD JURÍDICA Y FE PÚBLICA. VII. AUTONOMÍA PRIVADA Y APELLIDOS. VIII. INTERÉS SUPERIOR DEL MENOR Y APELLIDOS: 1. Distintas respuestas dependiendo de las circunstancias, a falta de acuerdo entre los progenitores. 2. El interés superior del menor reside, normalmente, en mantener como primer apellido el que se le impuso al nacer. 3. ¿Cuándo el interés superior del menor reside en que se le imponga como primer apellido el de su padre? IX. COMENTARIO CRÍTICO DE LA STC 178/2020, DE 14 DE DICIEMBRE. X. CÓMO AVANZAR PARA CONSEGUIR UNA EFECTIVA IGUALDAD POR RAZÓN DE SEXO EN LA IMPOSICIÓN DE APELLIDOS. BIBLIOGRAFÍA.

\section{PLANTEAMIENTO Y OBJETIVO}

La mecha que prendió mi interés para enfrentar este trabajo de investigación fue la publicación en el Boletín Oficial del Estado de la Sentencia del Tribunal Constitucional, Sala Segunda, 178/2020, de 14 de diciembre (magistrada ponente, doña Encarnación Roca Trías) ${ }^{1}$. En ella se resolvió el recurso de amparo presentado por la madre de una niña que había reclamado en la instancia la determinación judicial de la filiación paterna (asunto que no fue problemático esclarecer), y había obtenido pronunciamientos, de la Audiencia Provincial de Madrid y del Tribunal Supremo, que ordenaban, una vez determinada la paternidad del demandado, que se impusiera a la niña, como primer apellido, el paterno en lugar del materno con el que se la venía

1 BOE del 26 de enero de 2021. En la base de datos de Aranzadi se hace constar, por error, que la sentencia es del Pleno y que su ponente es Juan José González Rivas. 
identificando desde la inscripción del nacimiento en el Registro Civil ${ }^{2}$. Los derechos fundamentales invocados como vulnerados en este caso, tanto por la SAP Madrid, sección 24a de 3 de junio de 2015, como por la STS, Sala de lo Civil, de 23 de noviembre de $2017^{3}$, fueron dos: el derecho a la tutela judicial efectiva de la recurrente (art. 24.1 CE), en relación con el principio de protección integral de los hijos y del superior interés del menor (art. 39 $\mathrm{CE}$ ), y el derecho a la propia imagen del menor (art. 18.1 CE) — que ya habían sido objeto de interpretación, conectados con el orden de los apellidos de la persona, en la STC 167/2013, de 7 de octubre (ponente: don Juan José González Rivas) - . El Tribunal Constitucional estimó el recurso de amparo interpuesto por vulneración del derecho a la tutela judicial efectiva, en relación con el derecho a la propia imagen y a la protección integral de los hijos, ya que no se resolvió la controversia atendiendo al interés superior del menor; y, tras anular las sentencias de Audiencia y Tribunal Supremo, ordenó la retroacción de las actuaciones hasta el momento procesal oportuno para que pueda dictarse una nueva sentencia, por la Audiencia Provincial, respetuosa con el derecho fundamental vulnerado.

El caso es muy atractivo por dos motivos, en mi opinión.

En primer lugar, porque, así expuesto, pareciera que nuestros tribunales civiles se encuentran anclados en la tesis de anteponer el apellido paterno al materno cuando se determina la paternidad de un menor de edad de manera sobrevenida, como si rigieran todavía normas positivas ya superadas y desconociendo el valor superior del interés superior del menor. Pero, en realidad, la Sala Primera del Tribunal Supremo lleva varios años (antes incluso de que entraran en vigor los preceptos que, formalmente, han borrado de nuestro ordenamiento la preferencia del apellido paterno) insistiendo en que, con arreglo a ese interés y como regla general, el hijo debe conservar como primer apellido el que se le impuso al nacer. La resistencia a dar prioridad a este interés sí la apreciamos en determinados juzgados y audiencias, a tenor del número de recursos de casación interpuestos por las madres, como representantes legales de sus hijos menores, que han conformado la jurisprudencia

2 El Tribunal Constitucional había acordado la admisión a trámite de la demanda de amparo por si pudiera darle ocasión para aclarar o cambiar su doctrina, como consecuencia del surgimiento de nuevas realidades sociales (véase antecedente 4, STC $178 / 2020$, de 14 de diciembre). Y es que, como veremos, tenemos varios pronunciamientos previos en los que no ha sido todo lo conclusivo que cabía esperar, teniendo en cuenta los principios constitucionales afectados por el orden en que deben imponerse los apellidos a los hijos.

3 STS 638/2017, de 23 de noviembre (RJ 2017, 5079); ponente: Excmo. Sr. D. Eduardo Baena Ruiz. 
sobre la que después me detendré. En la mayoría de las sentencias que, desde 2015 (momento en que el problema llegó a casación), el Tribunal Supremo ha dictado en relación con el orden de los apellidos, se ha resuelto a favor de las madres, y solo en contadas ocasiones, atendiendo a las circunstancias del caso, se ha considerado que la identificación del menor con el primer apellido paterno responde mejor a su interés superior o ese primer apellido paterno debe ser impuesto porque así lo han acordado los progenitores. Precisamente en la STS 638/2017, que es la recurrida en amparo, es el acuerdo entre los progenitores lo que determina la solución alcanzada, aunque el razonamiento se contaminó (si se me permite la expresión) con la exclusión, o no, del efecto preclusivo de la demanda y la contestación a la demanda en los procesos de filiación, cuyo resultado incide en la identificación de la persona porque la filiación determina sus apellidos; tema procesal sobre el que se había pronunciado con anterioridad el Tribunal Constitucional en su Sentencia 242/2015, de 30 de noviembre (ponente: don Fernando Valdés Dal-Ré), aparentemente en sentido inverso a como lo ha hecho ahora en su Sentencia 178/2020, de 14 de diciembre.

En segundo lugar, porque desde la perspectiva de las varias sentencias dictadas por el Tribunal Constitucional en que debían analizarse vulneraciones de derechos fundamentales en el trámite de identificación de la persona por medio de sus apellidos (cuando se determina judicialmente la paternidad tras el ejercicio de una acción de reclamación), se confirma que el debate sobre el interés superior del menor ha eclipsado el de la posible discriminación por razón de sexo. $\mathrm{O}$, dicho con otras palabras, que a través del desarrollo de ese criterio como faro para decidir el orden de los apellidos, a falta de acuerdo entre los progenitores (el otro mantra en esta materia), parece que quiere conseguirse la plena equiparación de mujer y hombre en la transmisión preferente de su primer apellido a los hijos tenidos en común, aunque es una convidada de piedra en todas esas sentencias: unas veces porque no ha sido invocada la vulneración del art. $14 \mathrm{CE}$, como en la más reciente, y otras veces porque no se consigue del Tribunal Constitucional un pronunciamiento explícito a pesar de requerirlo la recurrente, como en las mencionadas SSTC $167 / 2013$, de 7 de octubre, y 242/2015, de 30 de noviembre, y previamente en la STC 176/2012, de 11 de octubre (ponente: don Andrés Ollero Tassara), que inadmitió el recurso de amparo por no justificarse la trascendencia constitucional de la demanda de amparo (en el caso León Madrid contra España, resuelto por la reciente STEDH de 26 de octubre de 2021, también inadmitió el Tribunal Constitucional el recurso de amparo interpuesto por la madre por falta de justificación de su trascendencia constitucional, pero el TEDH sí ha considerado merecedora de tutela fundamental la pretensión de la recurrente para que se mantuviera como primer apellido del hijo el suyo). Postura de 
perfil, del Tribunal Constitucional, que no resulta tan extraña si nos fijamos en la escasa relevancia dada por los autores a un posible problema de discriminación en la aplicación del art. 53 LRC de 8 de junio de 1957, en su primitiva redacción, o el art. 194 del Reglamento del Registro Civil de 14 de noviembre 1958 después de la aprobación de la Constitución Española en $1978^{4}$, que probablemente refleje el desinterés de la sociedad por alterar un estado de cosas que no se considera especialmente hiriente (a diferencia, por ejemplo, de la discriminación de los hijos en razón de su origen legítimo o natural, términos que desaparecieron de nuestro ordenamiento en 1981$)^{5}$. Solo detectamos un (cierto) cambio de mentalidad a partir de la aprobación de la Ley del Registro Civil de 21 de julio de 2011, informada expresamente por el principio de no discriminación por razón de sexo en la imposición de los apellidos, que se traduce en el aumento de la conflictividad ante los tribunales apreciada desde entonces; conflictividad que se agravó por la demora en la entrada en vigor del art. 49.2 LRC/2011 (hubo que esperar al 30 de junio de 2017), y que persistirá mientras el legislador no establezca reglas claras que iluminen a los aplicadores del derecho (encargados del Registro Civil y jueces)

4 Aunque hoy nos pueda parecer obvio el trato desigual, no lo era en los años ochenta y noventa, pues la doctrina no dedicaba especial atención al tema aun después de aprobada la Constitución, y tampoco se le dedicó demasiada en tratados posteriores. Es ejemplificativa del escaso interés la opinión de Rivero Hernández (1993: 432) cuando al explicar la novedad de la posible inversión de los apellidos por el hijo mayor de edad, no la regla única entonces vigente sobre imposición de los apellidos, apunta que con ello se intenta «atenuar la posible discriminación en contra del apellido materno por figurar en primer lugar el paterno (art. 53 LRC), que da lugar a que desaparezca inevitablemente el de la madre en la segunda generación» (las cursivas son mías), norma criticada entonces, además, por contradecir el principio de inmutabilidad del nombre. Ya más recientemente, Álvarez González y García Rubio (2013: 491) se limitan a señalar que la Ley del Registro Civil ha prescindido del criterio de la preferencia del apellido paterno y ha optado por un criterio neutral, como es el interés superior del menor. Tampoco en los comentarios específicos de la legislación registral encontramos opiniones contundentes, aunque se mencione el posible problema; así, Salvador Gutiérrez en sus comentarios a los arts. 53 y 55 LRC/1957 (1997) y el art. 194 RRC (2005), con la experiencia que da su labor como encargada del Registro Civil.

5 Ha sido resaltada por alguna autora la aplicación acrítica por los tribunales que resolvían las demandas sobre reclamación de la filiación paterna, durante muchos años, del art. 194 RRC, en contra del principio de jerarquía normativa, y la paradoja de que el Tribunal Constitucional y el Tribunal Supremo, al poner término a esa situación, hayan soslayado pronunciarse sobre la vulneración del derecho a la igualdad de trato (Artacho Martín-Lagos, 2018). 
tanto al inscribir al nacido como después, cuando se determina la segunda relación de filiación.

En realidad, todas las últimas reformas legales en materia de imposición de apellidos (desde la aprobación de la Constitución) han estado presididas por el principio de no discriminación por razón de sexo, aun reconociendo (las dos primeras, de 1981 y 1999) que se quedaban muy cortas. Tanto la previsión de la posible inversión del orden de los apellidos por el hijo mayor de edad y del acuerdo entre los progenitores para decidir el orden en que se transmite su primer apellido al hijo como la regla subsidiaria del interés superior del menor como criterio a tener en cuenta en caso de falta de acuerdo entre los progenitores, son reflejo de ese objetivo del legislador conforme con los tiempos actuales. Esta preocupación por superar costumbres y normas consideradas patriarcales lo advertimos en otros ordenamientos cercanos, como el francés o el italiano. Sin ánimo (ni espacio) para profundizar en estos dos ejemplos comparados, sí me parece muy ilustrativo colocar sus avances como pórtico de este estudio.

Sin duda puede servirnos de ejemplo, para una futura reforma, la que ha experimentado en el verano de 2021 el Código Civil francés (ha entrado en vigor el 2 de septiembre) $)^{6}$, con reglas muy interesantes en los arts. 311-21 y 311-23 que tratan de eliminar la preferencia por el apellido paterno (aunque no se consigue del todo y los supuestos legales son ambiguos) sin complicar demasiado la fijación de la identidad de la persona (complicación que, sin duda, introduce en el ordenamiento español el criterio del interés superior del menor como criterio subsidiario). El art. 311-21 del Code ha mantenido el principio de libre elección del apellido de familia cuando se determina conjuntamente la doble filiación, de modo que pueden decidir los progenitores que sea solo el del padre, solo el de la madre o la unión de ambos en el orden deseado; a falta de declaración conjunta, el apellido será el del progenitor cuya filiación se determine en primer lugar (a salvo el acuerdo permitido por el art. 311-23 cuando se determina la segunda filiación del hijo menor de edad de manera sobrevenida), aunque será el del padre si se determinan ambas filiaciones de manera simultánea (este es el único rastro, formal, que todavía queda de preferencia legal del apellido paterno); en caso de desacuerdo cuando se determinan simultáneamente las dos relaciones de filiación, el apellido se formará con los dos de los progenitores, unidos por orden alfabético. Con esta norma en la mano, los casos más problemáticos que están resolviendo nuestros tribunales serían de fácil solución, porque se mantiene el apellido que se le hubiera impuesto al nacer al hijo (normalmente

6 Loi no 2021-1017, du 2 août 2021. 
el de la madre) cuando después se determine la segunda filiación y no haya acuerdo entre los progenitores. Solo habría problemas si, debido a cambios de opinión — como veremos ocurre en casos españoles—, se discutiera la existencia o no de acuerdo.

Por lo que respecta a Italia, ha sido su Corte Costituzionale la que ha debido mover ficha, ante la falta de reacción del legislador a la inercia de imponer el apellido paterno, siendo reseñable la Sentencia 286/2016, de 21 de diciembre, que declara inconstitucionales los preceptos que no permiten a los progenitores llegar a un acuerdo para que se imponga a su prole el apellido materno; sin embargo, a falta de acuerdo se sigue salvando la preferencia del apellido paterno mientras el legislador no prevea otra posibilidad'. El 11 de febrero de 2021, la Corte Costituzionale acordó que debía estudiar la constitucionalidad del art. 262, párrafo primero del Codice, que no permite a los progenitores asignar al hijo, nacido fuera del matrimonio pero reconocido por el padre, el solo apellido materno (cuestión de constitucionalidad planteada por el Tribunal de Bolzano) ${ }^{8}$.

En fin, de cómo está el panorama en el momento presente en nuestro país, atendiendo a la legislación, la jurisprudencia y la doctrina constitucional (también a la doctrina de la Dirección General de los Registros y del Notariado, o de Seguridad Jurídica o Fe Pública como se ha decidido llamar por el actual Gobierno de la Nación) sobre qué apellido debe imponerse como primero de los dos del hijo, sin olvidar de dónde venimos y a dónde sería deseable ir, es de lo que me propongo escribir a continuación.

\section{PRIUS: EL DERECHO AL NOMBRE COMO DERECHO DE LA PERSONALIDAD}

El nombre es un derecho de la personalidad (ha sido reconocido explícitamente por el art. 50.1 y 2 LRC/2011 — toda persona tiene derecho a un nombre desde su nacimiento; las personas son identificadas por su nombre y apellidos-) que goza de la máxima protección internacional como integrante de la vida privada de la persona (art. 7 de la Carta de Derechos

7 Un completo, y a la vez sintético, estudio de la situación italiana en Cicero (2018: 245-258). La sentencia citada en el texto puede encontrarse en Diritto di Famiglia e delle Persone (2017/1). Vid. también la STEDH de 7 de enero de 2014, caso Fazzo contra Italia (TEDH 2014, 2).

8 Puede encontrarse la resolución en Diritto di Famiglia e delle Persone (2021/2). Un resumen de la noticia en De Angelis (2021). 
Fundamentales de la Unión Europea y art. 8 del Convenio Europeo para la Protección de los Derechos Humanos y de las Libertades Públicas) 9 .

El nombre puede también considerarse contenido del derecho a la propia imagen del art. 18 de la Constitución española (como han declarado las SSTC 167/2013, de 7 de octubre y 178/2020, de 14 de diciembre), si bien es más defendible entender el derecho al nombre como un derecho de la personalidad de carácter autónomo (Ordás Alonso, 2014: 77). Las reglas que lo disciplinan afectan, sin duda, a la esfera privada de las personas, pero tienen un componente público importante.

No puede identificarse a una persona sin darle un nombre (en sentido amplio, comprensivo de nombre y apellidos), que ha de ser la primera mención en la inscripción de la persona, y dicho nombre debe ser conforme con la dignidad garantizada por el art. $10 \mathrm{CE}$. Lo que puede decidir cada ordenamiento son las reglas de asignación del nombre. En España, no es objeto de discusión ninguna que el nombre está compuesto por dos apellidos, que vienen determinados como regla general por la filiación de la persona (art. 109 CC). Pero sí es objeto de debate el orden en que ha de imponerse el respectivo apellido de cada progenitor, cuando se determinan ambas filiaciones y ambos progenitores tienen derecho a transmitir su apellido al hijo ${ }^{10}$. Porque es indudable que, salvo excepciones muy notables, el primer apellido identifica más que el segundo, $\mathrm{y}$ «marca» a la persona como hijo del padre o de la madre.

El Tribunal Constitucional puso en valor, correctamente, el valor identificador del primer apellido de una persona, para conceder el amparo a una

9 Entre las más recientes sentencias, puede consultarse la STJUE de 2 de junio de 2016 (TJCE 2016, 102), y la STEDH de 26 de octubre de 2021, caso León Madrid contra España (versión en francés en https:/www.eldiario.es/sociedad/tribunal-estrasburgo-considera-discriminatoria-prevalencia-apellido-paterno-madre_1_8430681. html\#sentencia, leída el 11.11.2021). Hizo un acercamiento riguroso al derecho al apellido a partir de otro caso con relevancia internacional, desde la triple perspectiva de la tradición, la igualdad y la ciudadanía europea, Egusquiza Balmaseda (2005). Véase también Verdera Server (2013: 1132, nota 5). Sobre la consideración del derecho al nombre y los apellidos como derecho fundamental, véase Romero Coloma (2013).

10 Recordemos que no ostentará derechos por ministerio de la ley respecto de su hijo el progenitor condenado por sentencia firme a causa de las relaciones a que obedezca la generación o cuando la filiación haya quedado determinada contra su oposición, y en particular no ostentará el hijo, en ambos supuestos, el apellido del progenitor en cuestión más que si lo solicita él mismo o su representante legal (art. $111 \mathrm{CC}$ ). 
madre que combatió contra la legislación positiva entonces vigente ${ }^{11}$. Un razonamiento valioso de la STC 167/2013, de 7 de octubre, fue diferenciar dos situaciones: la que se da en caso de desacuerdo entre los progenitores en el momento en que se inscribe el nacimiento del hijo, y la que se da cuando el desacuerdo se plantea en el proceso judicial de determinación de la paternidad, después de haberse ya identificado a la persona con unos apellidos. Porque, efectivamente, en este segundo momento cabe hablar de un derecho a conservar el nombre que ya se ostentase (por más que la determinación sobrevenida de la paternidad debe desplegar efectos también en los apellidos): como concluye el Tribunal Constitucional, reconociendo la vulneración del contenido constitucional del art. $18 \mathrm{CE}$, «debió ponderarse especialmente el interés del menor y su derecho fundamental al nombre como integrante de su personalidad, a la hora de decidir sobre el orden de los apellidos» $\left(\mathrm{FJ} 7^{\circ}\right)^{12}$.

\section{DE DÓNDE VENIMOS}

En la Ley del Registro Civil de 8 de junio de 1957 se siguió el sistema tradicional, incluyendo algunas novedades, como la de apellidos del hijo natural o del adoptivo, que «responden a intereses sentimentales muy atendibles» (así se declara expresamente en la exposición de motivos, apdo. VI, de dicha ley) $)^{13}$. Ese sistema tradicional, presidido por el principio según el cual la filiación determina los apellidos (principio que permanece, a día de hoy), contenía una regla fundamental en el art. 55.I LRC/1957 que se sustentaba en la distinción, entonces aceptada, entre filiación legítima y filiación natural (los

11 La recurrente en amparo combate la aplicación que han hecho juzgado y Audiencia Provincial de los arts. 113-2 del Código Civil catalán, arts. 109 CC y 55 LRC/1957, enfocados desde los arts. 14 y $18 \mathrm{CE}$, pues, en defecto de acuerdo entre los progenitores, la preferencia del apellido paterno frente al materno supondría una vulneración del principio de igualdad y de la prohibición de discriminación por razón de sexo, así como del derecho a la propia imagen del menor.

12 En esta sentencia se considera relevante la alegación de la recurrente sobre la condena del padre como autor de un delito de violencia en el ámbito familiar como circunstancia para apoyar el mantenimiento del apellido materno $\left(\mathrm{FJ} 8^{\circ}\right.$ ). El tratamiento del cambio de los apellidos como consecuencia de la condena al padre por violencia de género ha sido distinto bajo la vigencia de la LRC/1957 y en la legalidad vigente. Para una aproximación resumida, véanse Minero Alejandre (2020) y Vela Sánchez (2020). Se ha planteado el problema, por ejemplo, en la SAP Valencia, Sección 7a, de 4 de diciembre de 2019 (AC 2020, 1111).

13 Hace un repaso histórico interesante sobre la imposición de apellidos en España, Torrelles Torrea (2016: 188-190). 
hijos ilegítimos ni siquiera tenían derecho al apellido del progenitor): antes de su reforma en 1999, dicho artículo preveía que la filiación legítima o natural determinaba los apellidos, matizando que los hijos naturales reconocidos solo por el padre tenían los apellidos por el mismo orden que este y, los reconocidos solo por la madre, los de esta, si bien podía invertirse su orden.

La Ley 40/1999, de 5 de noviembre, sobre nombre y apellidos y orden de los mismos, redactó el art. 55 LRC/1957 acomodándolo, tarde y mínimamente, a las exigencias derivadas de la no discriminación por razón de filiación y por razón de sexo, tanto del art. 14 CE como de la Ley 11/1981, de 13 de mayo. La desaparición en nuestro Código Civil de toda referencia a hijos legítimos, ilegítimos o naturales debía trasladarse también a la legislación registral, y ya sin calificativos el art. 55.I LRC/1957, en la versión que le dio el art. 3 de la Ley 40/1999, estableció que la filiación determinaba los apellidos, y que el único progenitor, cuando se determinaba solo una filiación, podía determinar, al tiempo de la inscripción, el orden de los apellidos. Mientras que la sociedad española de 1981 consideraba repelentes, por discriminatorios por razón del origen de la filiación, los ignominiosos términos de hijo natural o ilegítimo, el tradicional uso del apellido paterno antes que el materno, igualmente discriminatorio pero por razón de sexo, parecía no incomodar demasiado a esa misma sociedad (Torrelles Torrea, 2016: 190). Conviene resaltar, respecto de esta tolerancia social que, aun menor, todavía podemos advertir en la actualidad, que ni las tradiciones ni las actitudes sociales mayoritarias justifican una diferencia de trato basada en el sexo, y así lo ha resaltado la STEDH de 26 de octubre de 2021, caso León Madrid contra España (parágrafo 66).

Por su parte, el art. $194 \mathrm{RRC/} 1958$ preveía expresamente que el primer apellido del nacido era el del padre y el segundo el de la madre, con la salvedad (tras su reforma por Decreto 193/2000, de 11 de febrero) de la opción prevista por el art. 109 CC a partir de su reforma en 1999, que menciono inmediatamente. Y es muy significativo del escaso interés en adecuar nuestra legislación al principio de no discriminación por razón de sexo que en el año 2000 se mantenga por el legislador, sin recato ninguno, la preferencia del apellido paterno sobre el materno.

\section{HITOS LEGALES QUE BUSCAN SUPERAR LA HISTÓRICA PREVALENCIA DEL APELLIDO PATERNO}

\section{LAS REFORMAS DE 1981, 1999 Y 2011}

Desde la aprobación de la Constitución española en 1978, cabe hablar de tres hitos legales en la evolución de nuestro ordenamiento para superar 
la tradicional regla de prevalencia del apellido paterno sobre el materno. En los dos primeros intentos se trató de conseguir una mayor igualdad a través de la entrada de la autonomía privada en una materia considerada tradicionalmente como indisponible; $y$, en el tercero, se recurrió al interés superior del menor como panacea para actuar en caso de falta de acuerdo entre los progenitores. Y así, primero se previó, en 1981, la posible inversión de los apellidos por voluntad del hijo mayor de edad (art. 109 CC). Después, en 1999, se admitió el acuerdo entre los progenitores para decidir, al inscribir a su hijo en el Registro, el orden de sus apellidos (art. 109 CC y art. 55 LRC/1957) ${ }^{14}$. Por último, en 2011, en la nueva Ley del Registro Civil, se añadió que, en defecto de acuerdo entre los progenitores antes de inscribir el nacimiento del hijo común, el criterio a tener en cuenta debía ser el interés superior del menor (art. 49.2 LRC/2011) ${ }^{15}$. Con esta última disposición legal parece que se consigue desterrar formalmente del ordenamiento la histórica preferencia por el apellido paterno, pero en los cinco años transcurridos desde el 30 de junio de 2017 (fecha de su entrada en vigor) hasta la actualidad, solo el $0,5 \%$ de los bebés nacidos en España, inscritos en el Registro Civil, llevan como primer apellido el de la madre y como segundo el del padre (9.839 de 1.950 .000$)^{16}$.

El principio de no discriminación por razón de sexo reconocido por el art. $14 \mathrm{CE}$, con eficacia directa desde que entró en vigor la Constitución y que, por ello, podría haberse alegado para interpretar la legalidad vigente entonces en materia de imposición de apellidos y haber impulsado una reforma legal ${ }^{17}$, solo comenzó tímidamente a informar nuestra legislación con la regla

14 Mercedes Bengoechea recuerda la respuesta que dio en 1998 el Defensor del Pueblo a un matrimonio navarro que pretendía poner el apellido de la madre como primer apellido de su hija, excluyendo totalmente el juego de la autonomía de la voluntad (Bengoechea, 2006: 7).

15 Para una exposición muy sintética de las reglas sobre imposición de apellidos, véase Quicios Molina (2021). También es interesante la lectura de Barber Cárcamo (2010).

16 La noticia más reciente que me consta, publicada el 30 de abril de 2021, es de elDiario. es, que tiene como fuente el Ministerio de Justicia: https://bit.ly/3C3EuBd (consulta: 30 de septiembre de 2021). También el Ministerio de Interior proporciona estadísticas en que se apoyan otras informaciones periodísticas, como la que publicó el 2 de julio de 201820 minutos.es, que puede encontrarse en el siguiente enlace: https://bit. ly/3DYflZm (consulta: 30 de septiembre de 2021).

17 Ni siquiera se extrajeron consecuencias del art. 4 de la LO 3/2007, de 22 de marzo, para la igualdad efectiva de mujeres y hombres, que compelía a una interpretación y aplicación de las normas jurídicas que garantizase la igualdad de trato entre mujeres y hombres, como principio informador del ordenamiento jurídico. ¿Por qué no se 
contenida en el art. 109 CC (tras su reforma por la Ley 11/1981, de 13 de mayo), claramente insatisfactoria, que permite al hijo, al alcanzar la mayoría de edad, invertir el orden de sus apellidos, y anteponer, en consecuencia, el apellido materno al paterno.

Nuestro ordenamiento dio un paso importante en favor de la equiparación del apellido materno con el paterno con la Ley 40/1999, de 5 de noviembre, sobre nombre y apellidos y orden de los mismos (que entró en vigor a los tres meses de su publicación en el $B O E$ — véase la disposición final única-, por tanto ya en el año 2000), al aceptar el acuerdo de los progenitores para decidir el orden de los apellidos al inscribir al nacido. Se reforman los arts. 109 CC y $55 \mathrm{LRC} / 1957$ precisamente con la finalidad declarada de conseguir un sistema más justo y menos discriminatorio que el vigente hasta entonces (véase la exposición de motivos; las cursivas son mías). Reconoció el legislador en 1999 que la preferencia, en todo caso, del apellido paterno sobre el materno, que no se cohonestaba con el art. $14 \mathrm{CE}$, ya se había tratado de superar, sin éxito, en la reforma de la filiación introducida por la Ley 11/1981, de 13 de mayo $^{18}$. Y se entendió que el principio de no discriminación por razón de sexo se garantizaba, mínimamente, con una regla que daba entrada, en esta materia tradicionalmente considerada de orden público (por afectar a la identidad de las personas), a la autonomía de la voluntad de los progenitores en la imposición de los apellidos.

No será, sin embargo, hasta la nueva Ley del Registro Civil, de 21 de julio de 2011, que se consiga, al menos formalmente, una plena equiparación entre los progenitores que transmiten sus apellidos al hijo ${ }^{19}$. Si bien su regla de oro sobre el orden de los apellidos de las personas inscritas en un Registro español (contenida en el art. 49.2), consistente en optar por el criterio del interés superior del menor, y no por el apellido paterno, en caso de falta de acuerdo entre los progenitores, todavía tardó unos años en entrar en vigor (30 de junio

vio hasta 2017 la prevalencia del apellido paterno como «totalmente discriminatoria» (así la calificó en 2018 Corera Izu)? También incidió en la discriminación de la regla positiva vigente hasta 2017, Berrocal Lanzarot (2017).

18 Con posterioridad a la Ley $11 / 1981$ se presentó una proposición de ley (17 de septiembre de 1985) que proponía una redacción del art. 109 CC semejante a la que se aprobó en 1999 (referencias en Torrelles Torrea, 2016: 191).

19 Máxima valedora del principio de igualdad en el orden de los apellidos, y su plena consecución con la Ley del Registro Civil de 2011, ha sido Linacero de la Fuente, quien titula precisamente así el capítulo referente a la imposición de apellidos (2013: 203); merece la pena el recorrido que hace por distintas legislaciones europeas en el momento en que escribe (2013: 207-212) y la narración de la tramitación parlamentaria del art. $49 \mathrm{RC} / 2011$ (2013: 212-219). 
de 2017). El arraigo social de la práctica de anteponer el apellido al materno, señalado por la doctrina (Torrelles Torrea, 2016: 192) y contrastado en la práctica a tenor de las informaciones periodísticas referidas más arriba, sin duda explica el desinterés del legislador en conseguir una plena equiparación del hombre y la mujer en su derecho a transmitir su primer apellido. Expresamente se hizo notar en la exposición de motivos de la nueva ley registral que «[c]on el fin de avanzar en la igualdad de género se prescinde de la histórica prevalencia del apellido paterno frente al materno permitiendo que ambos progenitores sean los que decidan el orden de los apellidos» (apdo. V, párrafo 2. ${ }^{\circ}$. En realidad, la nueva Ley del Registro Civil dio un paso más a favor de la igualdad del padre y la madre en la identificación de sus hijos comunes a falta de acuerdo entre ellos, pues permitir a los progenitores decidir el orden de transmisión de su respectivo primer apellido ya se había previsto en la reforma previa de 1999. En ese momento el legislador no se había atrevido a tocar la regla subsidiaria, a falta de acuerdo, lo que ciertamente dotaba de escasa fuerza negociadora a la mujer interesada en que su hijo llevase como primer apellido el suyo (la mujer sigue pudiendo negociar poco, en mi opinión, sobre la imposición de apellidos, debido a las convenciones sociales, pero con una regla legal de cierre que prefiere el apellido paterno deja en manos del padre todo el poder de decisión).

Ya antes de 2011 se podría haber llegado a una interpretación de la legislación registral más conforme con el principio de no discriminación por razón de sexo, con base en una reforma del art. 53 LRC/1957 en $2005^{20}$. Las dudas planteadas en relación con qué establecía exactamente la legislación registral a la que se remite el art. $109 \mathrm{CC}$, cuando el art. $53 \mathrm{LRC} / 1957$ fue ligeramente retocado por la Ley 13/2005, de 1 de julio, derivaban de un precepto legal que en lugar de disponer que las personas son designadas por su nombre y apellidos, paterno y materno (art. 53 LRC/1957, en su redacción primitiva), estableció que las personas son designadas por su nombre y apellidos, correspondientes a ambos progenitores (art. $53 \mathrm{LRC/1957,} \mathrm{tras} \mathrm{su} \mathrm{modificación} \mathrm{por}$ la Ley 13/2005). Con este tenor literal, en la Ley del Registro Civil no se podía encontrar la solución al caso de la falta de acuerdo entre los progenitores, cabía hablar de una laguna legal, y era muy discutible que el art. 194 RRC, de naturaleza reglamentaria, fuera conforme con la ley. Estaba, sin embargo, tan asentada la prevalencia del apellido paterno que la Dirección General de los Registros y del Notariado y las Audiencias Provinciales siguieron aplicando la

20 Es la tesis de Bercovitz Rodríguez-Cano (2014) y Ordás Alonso (2014: 68-69), que consideraban derogado tácitamente el art. 194 RRC por el art. 53 LRC/1957 tras su modificación en 2005 . 
regla del art. $194 \mathrm{RRC}^{21}$. Contra una de estas Sentencias, concretamente la SAP Palma de Mallorca de 18 de septiembre de 2007, se rebeló Josefa León Madrid hasta conseguir del TEDH la condena del Estado español por aplicar automáticamente, sin atender a las circunstancias del caso, una normativa discriminatoria que vulneraba el art. $14 \mathrm{CEDH}$, en relación con el art. 8 CEDH: la STEDH de 26 de octubre de 2021 le ha reconocido la indemnización reclamada en concepto de daños morales y todas las costas solicitadas, lo que supone un gran triunfo.

\section{LA ANÓMALA SITUACIÓN JURÍDICA DESDE EL 22 DE JULIO DE 2011 HASTA EL 30 DE JUNIO DE 2017}

Las reticencias a dar plena carta de naturaleza al principio de no discriminación por razón del sexo de los progenitores en la imposición de apellidos a los hijos se traslucen del tiempo que debió pasar para que entrara en vigor una norma que, analizada desde ese principio, parece obvia. No se entiende que las disposiciones sustantivas contenidas en el art. $49.2 \mathrm{LRC} / 2011$ (pues las disposiciones sobre imposición de apellidos en función de la filiación de la persona, a las que se remite el art. $109 \mathrm{CC}$, tienen esta naturaleza) no entraran en vigor inmediatamente, porque ninguna razón de las que aconsejaban la vacatio legis de tres años elegida por el legislador impedía esa vigencia desde julio de 2011 de las disposiciones contenidas en el art. $49.2 \mathrm{LRC} / 2011^{22}$. La regulación sobre orden de los apellidos era tan manifiestamente vulneradora del principio constitucional de no discriminación por razón de sexo (art. 14

21 Sin dudar de su legalidad aplica el art. 194 RRC la RDGRN de 28 de diciembre de 2010 (JUR 2011, 404864). Tomo de Torrelles Torrea (2016: 193-194) las referencias a varias Sentencias de Audiencias (la autora recoge más en su trabajo): SAP Vizcaya de 6 de febrero de 2013 (JUR 2014, 144440), SAP Guadalajara de 15 de octubre de 2013 (JUR 2013, 335546), SAP Las Palmas de 19 de febrero de 2014 (JUR 2014, 104834).

22 En palabras del legislador, "[1]a complejidad de la Ley y el cambio radical respecto al modelo anterior aconsejan un extenso plazo de vacatio legis, que se ha fijado en tres años, para permitir la progresiva puesta en marcha del nuevo modelo, evitando disfunciones en el tratamiento de la información registral y la implementación de la nueva estructura organizativa” (exposición de motivos, apdo. VII, párrafo 6. , LRC/2011). Efectivamente, se pasa de un sistema basado en la división del Registro Civil en secciones a un sistema fundado en registros individuales personales, con asignación de un código personal desde la primera inscripción que se practique. Y la intención del legislador de desjudicializar el Registro obliga a elegir nuevos funcionarios competentes, lo que no ha sido una tarea política fácil. 
CE) que sorprende la falta de voluntad política, ya en 2011, para aprobar una entrada en vigor como la que se previó para algunas disposiciones adicionales y finales de la nueva Ley del Registro Civil que establecían importantes reglas sustantivas sobre la persona —adquisición de personalidad del nacido desde el entero desprendimiento del seno materno, sin más requisitos; adquisición de la nacionalidad española por los nietos de exiliados durante la Guerra Civil y la dictadura; inscripción de defunción de desaparecidos durante la Guerra Civil y la dictadura (véase la disposición final décima, sobre entrada en vigor) ${ }^{23}$ -

Por cierto, la voluntad política favorable a los nuevos cambios demostrada por el legislador del Registro Civil en 2011 también contrasta con la del legislador que ha revolucionado nuestro derecho de la persona en 2021 al regular los apoyos a las personas con discapacidad, como evidencian las disposiciones transitorias relativas a los procedimientos en tramitación a la entrada en vigor de las nuevas leyes. Mientras que en la disposición transitoria primera de la Ley del Registro Civil se prevé que a los procedimientos y expedientes iniciados con anterioridad a la entrada en vigor de la nueva ley les será aplicable la Ley de 8 de junio de 1957 y las disposiciones dictadas en su desarrollo (transitoria en que se apoyaron distintos tribunales para continuar eligiendo, como mejor opción para el hijo, el apellido del padre en lugar del de la madre), en la disposición transitoria sexta de la Ley 8/2021, de 2 de junio, se ha dispuesto que los procesos relativos a la capacidad de las personas que se estén tramitando a la entrada en vigor de la ley se regirán por lo dispuesto en ella, especialmente en lo que se refiere al contenido de la sentencia. Y en esta disposición transitoria sexta se ha apoyado, precisamente, el Pleno de la Sala Primera del Tribunal Supremo para dictar su primera sentencia sobre el nuevo sistema de apoyos instaurado: en la importantísima Sentencia de 8 de septiembre de 2021, el Tribunal Supremo comienza ya a sentar jurisprudencia, entre otras cuestiones fundamentales, sobre la referente al valor que ha de darse a la oposición de la persona con discapacidad a recibir asistencia (se trata en el caso de una persona con síndrome de Diógenes).

23 Sí entró inmediatamente en vigor la reforma del art. 30 CC, sobre adquisición de la personalidad del nacido una vez producido el entero desprendimiento del seno materno (disposición final tercera LRC/2011), desapareciendo la necesidad de vivir 24 horas desde ese momento y que tuviera figura humana. También entró en vigor el día siguiente al de su publicación en el $B O E$ una previsión especial de adquisición de la nacionalidad española por los nietos de exiliados durante la Guerra Civil y la dictadura (disposición final sexta LRC/2011). Así como la especial inscripción de defunción de desaparecidos durante la Guerra Civil y la dictadura (disposición adicional octava LRC/2011). 


\section{RÉGIMEN LEGAL VIGENTE DESDE EL 30 DE JUNIO DE 2017}

Desde el 30 de junio de 2017 se encuentra en vigor la regulación actualmente vigente sobre los criterios a tener en cuenta para decidir si el primer apellido del hijo debe ser el del padre o el de la madre, o en general para decidir, cuando la filiación está determinada respecto de los dos progenitores (que pueden tener el mismo sexo) el orden en que se imponen al hijo sus respectivos primeros apellidos ${ }^{24}$. Partiendo de la regla tradicional en nuestro ordenamiento de que se imponen a la persona dos apellidos, y que estos se determinan por su filiación (art. 109 CC), los dos criterios elegidos por el legislador son: en primer lugar, al acuerdo entre los progenitores (con acierto mencionado tanto por el art. 109 CC, desde su reforma por la Ley 40/1999, como por el art. 49.2 LRC/2011); en defecto de acuerdo, el interés superior del menor (solo dispuesto por el art. 49.2 LRC/2011, al que se remite el art. 109 CC, y como criterio que debe tener en cuenta el encargado del Registro para identificar al nacido antes de su inscripción registral) ${ }^{25}$. El art. 49.2 LRC/2011

24 Es sabido que la Ley del Registro Civil de 21 de julio de 2011 ha ido entrando en vigor de manera caótica y con cuentagotas, hasta su plena vigencia a partir del 30 de abril de 2021. En concreto del art. 49.2, que fija los criterios generales sobre imposición de apellidos, se acordó el legislador en la Ley 4/2017, de 28 de junio, de modificación de la Ley 15/2015, de 2 de julio, de Jurisdicción Voluntaria, al ordenar la modificación de la disposición final cuarta de dicha Ley de Jurisdicción Voluntaria que en su momento había modificado ya la disposición final décima de la Ley 20/2011, de 21 de julio, del Registro Civil, relativa a su entrada en vigor. Con la nueva redacción que se les dio en 2017 a sendas disposiciones finales quedó establecido el 30 de junio de 2017 como fecha de la entrada en vigor del art. 49.2 LRC/2011. No obstante, hay cierta confusión sobre si entró en vigor el 15 de octubre de 2015 (en algún caso lo hemos visto, como argumento en la defensa de dar preferencia al apellido materno a partir de ese momento), porque en esa fecha sí entró en vigor el art. 49.1 LRC/2011. Con esta prevención ha de leerse, por ejemplo, la RDGSJFP de 20 de febrero de 2020 (28 $)$ - BMJ, 2.239: 18, abril de 2021 - se sostiene, por ejemplo, que el art. 49 LRC/2011 está vigente «en este punto» desde esa fecha: el punto en cuestión es la atribución de apellidos a quien adquiere la nacionalidad española, de acuerdo con el art. 194 RRC y a salvo la opción prevista en el art. 109 CC, y en el mismo sentido el art. 49 LRC/2011. En la RDGSJFP de 4 de marzo de 2020 (75 $)$, que exponemos infra, declara con claridad que el art. 49.2 LRC/2011 entró en vigor el 30 de junio de 2017.

25 En el Proyecto de la vigente Ley del Registro Civil se había optado por seguir el orden alfabético como criterio subsidiario, que era una de las alternativas sugeridas en el Informe del Consejo General del Poder Judicial al anteproyecto de ley; la solución finalmente acogida resultó de una transaccional de consenso en atención a la diver- 
dispone tales criterios para un concreto supuesto, que es cuando se inscribe al nacido, pero es defendible que tales criterios deban tenerse en cuenta, por analogía, cuando queda establecida legalmente la doble filiación de la persona que determina sus apellidos, aunque sea con posterioridad a la inscripción del nacimiento, y siempre, por supuesto, que el hijo siga siendo menor de $e^{e d a d^{26}}$. O cuando se determina la filiación adoptiva que tendrá trascendencia en la identificación de la persona: los apellidos del adoptado serán los de los adoptantes (o los del único adoptante), o uno de los apellidos será el del adoptante si siguiera quedando determinada una filiación por naturaleza (adopción del hijo del cónyuge) $^{27}$.

Pero cuando se determina la segunda filiación siendo ya mayor de edad el hijo, ningún juego puede dársele a estos dos criterios (acuerdo entre los progenitores o interés superior del menor) y el criterio que debe prevalecer es mantener como primer apellido el que ya tuviera la persona, por razones de estabilidad del estado civil y seguridad jurídica, salvo que el hijo prefiera anteponer el apellido paterno.

\section{EVOLUCIÓN DE LA DOCTRINA CONSTITUCIONAL Y DE LA JURISPRUDENCIA}

Hasta el 30 de junio de 2017, y aunque ya desde el 21 de julio de 2011 teníamos aprobada una regulación que superaba la preferencia del apellido paterno sobre el materno, es notoria la resistencia de los aplicadores del

sidad de reglas propuestas por los grupos parlamentarios en las numerosas enmiendas presentadas (Linacero de la Fuente, 2012).

Merece la pena transcribir la regla del art. 49.2 LRC/2011 que nos interesa, para incidir en el concreto supuesto regulado (antes de la inscripción registral) y la necesidad, por ello, de extender los principios que inspiran la regulación y, en concreto, los dos criterios elegidos a supuestos no previstos por el legislador, para de esa forma colmar la laguna legal: «Si la filiación está determinada por ambas líneas los progenitores acordarán el orden de transmisión de su respectivo primer apellido, antes de la inscripción registral.En caso de desacuerdo o cuando no se hayan hecho constar los apellidos en la solicitud de inscripción, el Encargado del Registro civil requerirá a los dos progenitores, o a quienes ostenten la representación legal del menor, para que en el plazo máximo de tres días comuniquen el orden de los apellidos. Transcurrido dicho plazo sin comunicación expresa, el encargado acordará el orden de los apellidos atendiendo al interés superior del menor» (las cursivas son mías).

27 El Código Civil catalán ha previsto reglas específicas sobre imposición de apellidos a los hijos adoptados (véanse los arts. 235-48.1). 
derecho a dejar de aplicar la regla registral donde expresamente se mantenía esa preferencia en caso de falta de acuerdo: el art. $194 \mathrm{RRC} / 1958$.

El Tribunal Constitucional, en su Sentencia 176/2012, de 11 de octubre, desaprovechó la ocasión de pronunciarse sobre el respeto, o no, del principio de igualdad por el art. $194 \mathrm{RRC}$, al inadmitir el recurso de amparo interpuesto por la madre con apoyo precisamente en la vulneración del art. $14 \mathrm{CE}$ por las sentencias que habían resuelto la imposición, como primer apellido de la hija, del apellido paterno, una vez determinada judicialmente la paternidad. Tanto la recurrente como el Ministerio Fiscal habían dado buenos argumentos para que fuera estimado el recurso de amparo, si bien se entendió por el Alto Tribunal que no se había satisfecho la carga de justificar la especial trascendencia constitucional del recurso ${ }^{28}$ (recordemos que contra un ATC con el mismo pronunciamiento se recurrió ante el TEDH en el caso León Madrid contra España, con el resultado que ya he expuesto más arriba -STEDH de 26 de octubre de 2021-). También en su Sentencia 167/2013, de 7 de octubre, el Tribunal Constitucional rehúye pronunciarse sobre la vulneración del principio de no discriminación, a pesar de haber sido invocado por la recurrente, y centra su análisis en la vulneración del derecho a la propia imagen del hijo que supone una decisión favorable a imponer como primer apellido el paterno una vez determinada judicialmente su paternidad (cuatro años después de la inscripción de nacimiento), pues el nombre forma parte de la propia imagen y tiene el menor de edad derecho a mantener su identidad (en este caso, el padre, además, había sido condenado por violencia de género). Es más, da por buena la regulación al mencionar expresamente, sin cuestionarlos, los dos criterios que deben regir la inscripción registral de los apellidos: el primero es el mutuo acuerdo entre los progenitores y el segundo «la inscripción de la filiación paterna y después la materna, como ha venido siendo usual en el ordenamiento jurídico civil»; y al explicar las normas registrales a tener en cuenta con referencia expresa al art. $194 \mathrm{RRC}^{29}$.

28 Artacho Martín-Lagos (2018) explica bien este primer recurso de amparo interpuesto en relación con el orden de los apellidos. Con acierto señala después la autora que es llamativa la falta de unidad de criterio de la Fiscalía ante el Tribunal Constitucional (defendió lo contrario en el recurso de amparo resuelto por la STC 167/2013, de 7 de octubre).

29 El Tribunal Constitucional quiso seguir reflexionando, no obstante, sobre la posible vulneración del derecho a la igualdad en esta materia, y por ello dio este motivo para admitir a trámite el recurso de amparo que condujo a la STC 242/2015, de 30 de noviembre, si bien se acabó inadmitiendo por defectos procesales. 
Tras esta sentencia del Tribunal Constitucional, la Sala Primera del Tribunal Supremo, y debido a los recursos presentados en esa época que discutían el statu quo vigente cuando se determinaba la paternidad tiempo después de la maternidad, comenzó en 2015 a sentar una jurisprudencia muy necesaria, para adaptar la legalidad a algunos de los principios constitucionales, vigentes desde 1978, aunque el razonamiento seguido tendía más bien a adelantar la aplicación de los criterios legales contenidos en la Ley del Registro Civil de 2011, y en particular el criterio del interés superior del menor, subsidiario del acuerdo entre los progenitores. Con un entendimiento del interés superior del menor, además, ciertamente favorable a mantener el apellido materno como primer apellido del hijo en la medida en que así se le identificó al nacer, pues se insiste en que no se trata de que no le perjudique el cambio al hijo, sino en que no le beneficia especialmente atendiendo a las circunstancias concurrentes ( $\mathrm{y}$ con independencia del tiempo transcurrido, aunque sea poco, el hijo ya ha disfrutado de su identidad en el ámbito familiar, social y, normalmente, escolar) — con rotundidad a partir de la STS 659/2016, de 10 de noviembre-. Así, en la STS 76/2015, de 17 de febrero, razonó que «en los aspectos sustantivos la vigencia constitucional de los principios que la inspiran [la LRC/2011] sí se encuentran en vigor», lo que "autoriza una interpretación correctora de la [legislación] vigente» aunque la LRC/2011 no hubiera entrado todavía en vigor ${ }^{30}$. El recurso al interés superior del menor, para justificar el mantenimiento, como primer apellido del hijo, el materno, podía conducir, en consecuencia, al respeto de algún principio constitucional, como el principio fundamental, reconocido por el art. $39 \mathrm{CE}$, de protección de los menores de edad. No se planteó el Tribunal Supremo, sin embargo, la posible derogación tácita del art. 194 RRC tras la reforma del art. 53.1 LRC/1957 en 2005, por ser contrario al principio de discriminación por razón de sexo, como se había propuesto desde 2014 por doctrina autorizada a la que ya he hecho referencia.

Volvió a rehuir la cuestión el Tribunal Constitucional en su STC $242 / 2015$, de 30 de noviembre, por no invocarse el principio de igualdad en la instancia, incumpliéndose el art. 44.1.c) LOTC $^{31}$. En el caso, el varón que

30 RJ 2015, 924. En el mismo sentido, y entre otras que después mencionaré, SSTS 620 y 621/2015, de 11 y 12 de noviembre (RJ 2015, 5606 y 5602), así como las SSTS 15/2016, de 16 de febrero, 659/2016, de 10 de noviembre, y 299/2017, de 16 de mayo. Siguieron su estela distintas sentencias de Audiencias, como la SAP Vizcaya de 6 de marzo de 2015 (AC 2015, 654), SAP Huelva de 20 de mayo de 2015 (AC 2015, 1235) o SAP Pontevedra de 11 de noviembre de 2015 (JUR 2015, 298500).

31 Como se describe en el FJ $1^{\circ}$ de esta sentencia, para la parte recurrente los arts. 194 RRC y 109 CC «vulneran de forma flagrante el principio de igualdad entre hombre 
reclama la determinación de su paternidad no matrimonial también solicitó expresamente en su demanda que se rectificase la inscripción registral para que después del nombre de la hija figurase como primer apellido el del padre. La madre demandada contesta que no se opone a la demanda, y que está conforme con la realización de la prueba biológica acordada por el juzgado, según consta en los antecedentes. Y es en el acto de la vista cuando solicita que se mantenga su apellido como primero de la hija. Veremos que el óbice de la preclusión procesal esgrimido en este caso para no entrar a conocer del asunto, no ha impedido que en la STC/178/2020, sobre la que después me detendré con más detalle para concluir este trabajo, se estime el amparo por vulneración del derecho a la tutela judicial efectiva de la madre y el derecho a la propia imagen de la hija.

\section{DOCTRINA RECIENTE DE LA DIRECCIÓN GENERAL DE SEGURIDAD JURÍDICA Y FE PÚBLICA}

Solo pretendo recoger aquí algunas resoluciones recientes que me han interesado por la escasa atención prestada por la Dirección General de Seguridad Jurídica y Fe Pública a la defensa de una verdadera igualdad material del hombre y la mujer en la concreta materia estudiada ${ }^{32}$. Son las últimas resoluciones publicadas (de hace un año) a las que podemos tener acceso consultando el Boletín del Ministerio de Justicia. Así, en una

y mujer, lo que no se corrige en las resoluciones judiciales recurridas que, además, tampoco valoran el consiguiente perjuicio ocasionado a la niña, que ve modificado el orden de sus apellidos». En esta ocasión, el Tribunal Supremo había inadmitido el recurso de casación interpuesto contra la sentencia de la Audiencia Provincial que había resuelto la imposición como primer apellido del paterno. Y el padre se defiende en amparo con el argumento, entre otros, de que la hija menor es la única titular del derecho a los apellidos y tanto el padre como la madre actúan en la misma posición de igualdad en el proceso; no existiría, por ello, vulneración del art. $14 \mathrm{CE}$. En este recurso de amparo el Ministerio Fiscal entendió vulnerado el principio de no discriminación por razón de sexo y el derecho a la propia imagen de la menor (art. $18 \mathrm{CE}$ ). Por su relación con el tema de estudio, también sugiero la lectura de la RDGRN de 11 de junio de 2001 (2a) — RJ 2002, 498—, que no accede a la conservación de los apellidos maternos de la menor reconocida dentro del plazo para inscribir el nacimiento (creo que con un exceso de rigor formal que no encontramos, afortunadamente, en la RDGRN de 10 de noviembre de 1990 - RJ 1990, 9314_, en un supuesto de inscripción fuera de plazo de nacimiento de menor declarado en desamparo). 
resolución de 14 de julio de 2020 (la 11.a), al resolver el recurso presentado por una ciudadana búlgara, nacionalizada española, y su exmarido, quienes solicitan que se le imponga a su hija la variante femenina del apellido materno (Medarova), y al gemelo de la niña la variante masculina (Medarov) ${ }^{33}$. Ambas variantes, dependiendo del sexo de la persona, son admisibles de acuerdo con la primera ley personal de la madre, si bien esta eligió la variante femenina al inscribirse como nacional española. La DG afirma que "parece que, finalmente, no está en discusión la aplicación del artículo 194 RRC, en el sentido de que el primer apellido de los españoles es el primero del padre y segundo apellido el primero de los personales de la madre» (apdo. III). Se afirma con rotundidad que la identidad de los apellidos de hermanos del mismo vínculo es uno de los principios rectores del sistema de atribución de apellidos español, porque así lo dispone la ley y ningún precepto reglamentario puede conducir a entender otra cosa (el art. $200 \mathrm{RRC})^{34}$, pero no se ve ningún problema en que se elija como primer apellido el paterno, no por acuerdo entre los progenitores (aunque este acuerdo existió, según consta en los hechos de la resolución, cuando se inscribe a los mellizos en febrero de 2017), sino en aplicación de un artículo reglamentario que podía ser considerado ilegal desde $2005^{35}$. Y en la RDGSJFP de 4 de marzo de 2020

33 BMJ, 2.243: 44, septiembre de 2021. Los gemelos se habían inscrito en febrero de 2017 con el primer apellido del padre español y el segundo apellido de la madre, entonces todavía Medarov.

34 Por cierto, la doctrina registral será menos estricta a partir de ahora con las variantes femenina y masculina de apellidos extranjeros, pues la resolución-circular de la DGSJFP de 19 de abril de 2021 ha modificado su criterio interpretativo del art. 200 RRC.

35 Dice en el apdo. IV la RDGSJFP: «la identidad de apellidos de hermanos menores del mismo vínculo establecida en normas de rango legal (cfr. los arts. 109 CC, 55 LRC y 49 de la Ley 20/2011, de 21 de julio del Registro Civil) no admite quiebra y prevalece sobre la regla de un precepto reglamentario. De manera que la posibilidad prevista en el artículo 200 RRC, ni es de aplicación automática ni cabe interpretarla aisladamente». El celo en que se aplique la ley lleva a la DG en este caso a ordenar que se modifique el segundo apellido de la niña para que sea Medarova (que es la variante por la que optó la madre al adquirir la nacionalidad española) y que se inicien de oficio las actuaciones precisas para cambiar el apellido de su hermano, atribuido en infracción de normas. Se ha mantenido la misma doctrina, en relación con la imposición al hijo menor de edad del apellido elegido por la madre, de origen ruso, al nacionalizarse española, la RDGSJFP de 15 de julio de 2020 (46a) — BMJ, 2.243: 49, septiembre de 2021 - Sobre la prevalencia del principio de identidad de apellidos entre hermanos del mismo vínculo sobre la regla del art. 200 RRC y su posible aplicación a los casos 
$\left(8^{a}\right)^{36}$, también sobre régimen de apellidos de los extranjeros nacionalizados, que es la práctica registral en la que se testan los principios que rigen nuestro sistema, se recuerda la doctrina de que, como los apellidos han de ser los determinados por la filiación del inscrito, si la filiación está determinada por ambas líneas, el primer apellido será el del padre y el segundo apellido el de la madre, aunque sea extranjera (art. 194 RRC).

Bien es verdad que, con la mejor de las miradas, podemos considerar deslices estos pronunciamientos indirectos, pues en una Resolución anterior la DGSJFP rechazó la aplicación del art. 194 RRC aunque, cuando ocurren los hechos, todavía no estaba en vigor la regla establecida por el art. 49.2 LRC/2011, y recurrió al interés superior del menor como criterio para resolver el conflicto suscitado entre el padre y la madre de un menor (inscrito con la sola filiación materna hasta que se determinó al poco tiempo la filiación paterna por reconocimiento del padre) en relación con el orden en que debían ser impuestos sus respectivos primeros apellidos. Efectivamente, en la RDGSJFP de 4 de marzo de $2020\left(75^{a}\right)^{37}$, enfrentada a un claro desacuerdo entre los progenitores en cuanto al orden de los apellidos de su hijo una vez que se ha determinado por reconocimiento la paternidad (ese reconocimiento se otorgó al mes de la inscripción y, consentido al poco por la madre, determinó la paternidad a los seis meses del nacimiento), y una decisión del encargado del Registro Civil que había aplicado automáticamente lo ordenado por el art. 194 RRC y fue recurrida por la madre (cuyo primer apellido se había impuesto también como primero de los del hijo), razona la Dirección General, siguiendo la jurisprudencia sentada a partir de la STS 76/2015, de 17 de febrero (en la que después incidiré) y recal-

en que hay variante femenina y masculina del apellido, véase también RDGRN de 17 de diciembre de 2019 (20a) - BMJ, 2.236: 41, enero de 2021-.

$B M J, 2.240$ : 32, mayo de 2021. En el caso, la interesada, filipina de origen que obtiene la nacionalidad española por residencia, solicita que se mantengan los apellidos que tiene atribuidos conforme a la legislación filipina: primero el de su padre y segundo el de su marido. No se acepta la petición por la Dirección General, porque la posibilidad de conservación ex art. 199 RRC de los apellidos impuestos con arreglo a otra legislación debe pasar el filtro del orden público internacional español (art. 12.3 CC), y tener el apellido del cónyuge no es admisible cuando la interesada tiene determinada tanto la filiación paterna como la paterna. En esta resolución se han recordado dos principios jurídicos rectores de nuestro ordenamiento que han sido aplicados por la Dirección General como integrantes de dicho orden público: el principio de la duplicidad de apellidos de los españoles y el principio de la infungibilidad de las líneas cuando existe filiación paterna y materna. $B M J, 2.240: 35$, mayo de 2021 . 
cando que en el momento de pronunciarse ya ha entrado en vigor la nueva regulación (el 30 de junio de 2017), que «la norma no debe interpretarse literalmente cuando lo que está en juego es el interés superior de un menor, debiendo ser este el criterio determinante siempre que se trate de adoptar cualquier medida que le afecte» (FD IV). ¿Y en qué se traduce, en el caso, ese interés superior del menor? Pues, en lugar de tomar partido, la Dirección General ordena la retroacción de las actuaciones para que sea el Encargado del Registro quien decida (cuatro años después del nacimiento) cuál debe ser el primer apellido del nacido, si el de la madre que se le impuso al nacer o el del padre que se le impuso cuando, seis meses después, se determinó la filiación paterna ${ }^{38}$.

$\mathrm{Ni}$ una palabra de un posible trato discriminatorio de la mujer, más allá de las referencias a la exposición de motivos de la Ley del Registro Civil de 21 de julio de 2011. Solo a través del recurso al interés superior del menor, en defecto de acuerdo entre los progenitores, la madre puede conseguir, si así lo demandan las circunstancias, que su primer apellido sea el primero de su hijo. Y entre esas circunstancias está que el auto del encargado del Registro Civil, ordenando inscribir como primer apellido del nacido el 18 de julio de 2016, el del padre, es de fecha 21 de noviembre de 2016. Y para la identidad de la persona, inspirada por el principio de determinación lo más inmediatamente posible (art. 7 de la Convención de los Derechos del Niño), no parece que este trasiego sea nada bueno.

En fin, el sesgo favorable a imponer el apellido paterno como primero del hijo lo encontramos claramente en la RDGRN de 22 de enero de 2016 $\left(29^{\mathrm{a}}\right)^{39}$ : inscrito el nacido por declaración del abuelo materno, autorizado por la madre, imponiéndole al nacido como primer apellido el materno, se accede a la petición del marido (que solo días después del nacimiento se presenta ante el Registro Civil) de que se aplique el art. 194 RRC dada la falta de acuerdo entre los progenitores.

38 Las únicas pistas que da la Dirección General son estas: i) lo relevante no es el deseo de los progenitores, sino el interés del menor en relación con el cambio de los apellidos con los que ha venido siendo identificado desde que nació (regla general); ii) en este caso, «debe tenerse en cuenta que el afectado fue inscrito inicialmente con una sola filiación conocida, atribuyéndole como primer apellido el primero de la madre, si bien el 30 de enero de 2017, cuando el menor contaba con poco más de seis meses, quedó inscrito la filiación paterna y la atribución de sus nuevos apellidos».

39 JUR 2016, 217912. Es muy interesante también la doctrina de la DGRN sobre la imposición de apellidos a ciudadanos hispano-lusos, que como es sabido son inscritos en Portugal con el apellido materno, con base en el art. 194 RRC; véase, entre otras, RDGRN de 29 de mayo de 2015 (12a) -JUR 2016, 40976-. 


\section{AUTONOMÍA PRIVADA Y APELLIDOS}

Con independencia de la caracterización del nombre como derecho de la personalidad, tradicionalmente se ha considerado la imposición de apellidos, como efecto automático de la determinación de la filiación de la persona y elemento permanente de la identidad de las personas, una cuestión de orden público, y como tal escasamente permeable al juego de la autonomía privada ${ }^{40}$. Sin embargo, aun pudiendo todavía considerar la imposición de apellidos como cuestión de orden público, con las consecuencias oportunas, es indudable el mayor juego permitido en los últimos años por la ley a la voluntad de los particulares, tanto la de la propia persona que puede invertir el orden de sus apellidos cuando alcance la mayoría de edad (aun una única vez) ${ }^{41} \mathrm{o}$ incluso solicitar la conservación de los apellidos que viniera usando tras la rectificación de su filiación (art. 53.5. $.^{\circ} \mathrm{LRC} / 2011$ ) — si se trata de un extranjero que adquiere la nacionalidad española, se le permite elegir el orden en que deben figurar en su inscripción los respectivos primeros apellidos de su padre y de su madre ${ }^{42}$-,

40 Se afirmó con rotundidad por las RRDGRN de 6 de febrero de 1991 y 7 de enero de 1995 (RJ 1991, 1661; 1995, 1451). Por ejemplo, en la Instrucción de la DGRN de 23 de mayo de 2007, sobre apellidos de los extranjeros nacionalizados españoles y su consignación en el Registro Civil español, se alude a la función de control público de la identidad del individuo que, históricamente, han venido desempeñando el nombre y los apellidos. Por otra parte, la automaticidad de la imposición de los dos apellidos que determine la filiación se cuestiona en la actualidad (Ruiz-Rico Ruiz, 2020). Sobre la trascendencia práctica que puede tener la eficacia automática de la determinación de la filiación en la imposición de los apellidos, véase SAP Málaga, Sección 7a a de 7 de mayo de 2020 (AC 2020, 1213), en un supuesto en que la hija, tiempo después de que quede determinada su paternidad, solicita que se le imponga el apellido paterno.

41 Lo ha repetido la DGRN en varias resoluciones. El principio de inmutabilidad de los apellidos quebró con esta facultad reconocida a cualquier inscrito, sin necesidad de alegar causa ninguna, por el art. 109 CC, al reformarse por la Ley 11/1981, de 13 de mayo. Pero la Dirección General de los Registros ha seguido entendiendo de manera estricta las causas tasadas de modificación de los apellidos (véase, por ejemplo, RDGRN de 27 de marzo de 2008 [JUR 2009, 381257]).

42 Lo ha declarado expresamente, por ejemplo, la RDGRN de 3 de diciembre de 2019 $\left(18^{\mathrm{a}}\right)$ - BMJ, 2.238: 27, enero de 2021—, en un caso en que la ciudadana brasileña que adquiere la nacionalidad española pretende conservar como segundo apellido el de su marido, y la RDGRN de 3 de diciembre de 2019 (19 $\left.{ }^{a}\right)$ - BMJ, 2.238: 29, enero de 2021 - en un caso en que la ciudadana rusa que adquiere la nacionalidad española pretende que se le reconozca como primer apellido el de su marido y como segundo el de uno de sus progenitores. Véase también RRDGRN de 12 de diciembre de $2019\left(6^{\mathrm{a}}\right.$ y $\left.7^{\mathrm{a}}\right)$ - BMJ, 2.238: 32 y 35, enero de 2021-, relativas a sendos casos 
como la de los progenitores que tienen el derecho-deber de dar un nombre a sus hijos (e inscribirlos en el Registro Civil).

Ese juego concedido a la autonomía de la voluntad sigue siendo excepcional, si estamos a lo razonado por la RDGSJFP de 4 de marzo de 2020 $\left(100^{\mathrm{a}}\right)^{43}$ para desestimar el recurso presentado contra la decisión del encargado que no había accedido a volver a invertir el orden de los apellidos de la solicitante. En 2009 se había conseguido la inversión con arreglo al art. 109 CC, y en 2016 se pretende retomar como primer apellido el del padre ${ }^{44}$. Pues bien, recuerda la Dirección General su consolidada doctrina de que la opción de invertir los apellidos se agota en su ejercicio:

[...] de modo que no cabe dejar sin efecto el orden de apellidos resultante por una nueva declaración de voluntad de signo contrario. Tal conclusión tiene su fundamento en el principio de seguridad jurídica, atiende a la final [sic] de garantizar la estabilidad del nombre y de los apellidos, signos de individualización e identificación de la persona cuya modificación queda sustraída a la autonomía de la voluntad de los particulares salvo en los casos excepcionales y taxativos determinados por la ley ${ }^{45}$.

Los progenitores tienen una oportunidad para decidir el orden en que sus respectivos primeros apellidos se transmiten al hijo, y la verdad es que no es nada habitual que se elija el materno como primero de los del hijo (lo que

en que los apellidos del naturalizado español provienen de una solo línea de filiación estando determinadas las dos.

BMJ, 2.240: 43, mayo de 2021.

44 El motivo para solicitarlo (que no causa, como se narra en los hechos de la resolución) es que la hija había pedido la inversión del orden de sus apellidos porque en ese momento su padre iba a ingresar en prisión y tenía mala relación con él, pero que ahora el afecto ha vuelto (además la solicitante va a contraer matrimonio y quiere que su primer apellido sea el que tenía cuando se inscribió su nacimiento). Motivos intrascendentes, porque la opción de invertir (una vez) el orden de los apellidos por el mayor de edad es libre.

Merece la pena recordar que ese principio de estabilidad de los apellidos preside la doctrina registral contraria a que el extranjero que opta por conservar sus apellidos al adquirir la nacionalidad española, ya sea mayor o menor de edad (en este último caso tiene dos meses tras alcanzar la mayoría de edad para solicitar que le sean impuestos los apellidos que hubieran correspondido conforme a su nueva ley personal) pueda ejercer la opción de invertir el orden de sus apellidos reconocida por el art. 109.III CC. Entre las más recientes, véase RRDGSJFP de 4 de marzo de $2020\left(74^{\mathrm{a}}\right.$ y $\left.76^{\mathrm{a}}\right)$ - BMJ, 2.240: 38 y 40, mayo de 2021- o RDGSJFP de 9 de junio de 2020 (67a) —BMJ, 2.242: 132, julio de 2021-. 
ha sido tildado de "patriarcado del consentimiento» por la filósofa Ana de Miguel). Interesante es el caso de la RDGRN de 12 de diciembre de 2019, en un caso en que madre y padre solicitan pocos días después de la inscripción de nacimiento que se anteponga el apellido materno al paterno, alegando un error de la gestoría que actuó como mandataria; sin éxito ninguno. $\mathrm{O}$ el caso de la RDGRN de 19 de septiembre de 2019 (7a): padre y madre acuden al Registro Civil para que se invierta el orden de los apellidos de sus hijas menores de edad, de modo que el materno sea el primero, alegando que las relaciones con la familia paterna se han deteriorado desde el nacimiento de la hija mayor, hasta el punto de que ha desaparecido cualquier trato, y que ambas menores son conocidas y se identifican a sí mismas con el apellido materno. No accede la DGRN a la solicitud, invocando como siempre la restricción para elegir la opción los progenitores (al inscribir el nacimiento), y sin que se haya probado suficientemente ese uso habitual del apellido materno como primero e identificador ${ }^{46}$.

Y esa oportunidad de acuerdo puede darse, en principio, cuando se presenta una demanda judicial de reclamación de paternidad expresándose en ella y en la contestación (o en el acto de la vista) la misma voluntad de los progenitores en relación con el tema del orden en que deben imponerse sus apellidos al hijo, una vez determinada la filiación ${ }^{47}$. No tengo ninguna duda de que un cambio de opinión del varón que ha aceptado que el apellido materno sea el primero del hijo no tendría ningún recorrido, porque se trata de una voluntad conforme a la regla que debería ser normal. Pero una voluntad de la madre favorable a que cambie el primer apellido de su hijo, y pase a ser el paterno, debe tratarse con mucha prevención, bien porque es discutible que la voluntad sea verdaderamente libre, bien porque no responde al interés superior del menor.

46 Respectivamente, $B M J, 2.236: 38$, enero de 2021, y $B M J, 2.233: 37$, septiembre de 2020.

47 En la RDGRN de 10 de noviembre de 2004 (4a) -JUR 2005, 73161 - se razonó que, como el acuerdo puede alcanzarse antes de la inscripción de la segunda filiación, la declaración por sentencia de que el primer apellido sea el materno equivale a dicho acuerdo a los efectos de excluir la aplicación de la regla subsidiaria del art. 194 RRC. Es interesante la resolución del caso de la SAP Madrid, Sección 22a , de 19 de febrero de 2021 (JUR 2021, 147342): el juzgado no se había pronunciado sobre los apellidos del hijo, una vez determinada judicialmente la paternidad, porque entendía que el tema debía plantearse en sede registral; la audiencia, por el contrario, se declara competente y estima el recurso del padre que invoca el acuerdo alcanzado (y después negado por la madre). 


\section{INTERÉS SUPERIOR DEL MENOR Y APELLIDOS}

\section{DISTINTAS RESPUESTAS DEPENDIENDO DE LAS CIRCUNSTANCIAS, A FALTA DE ACUERDO ENTRE LOS PROGENITORES}

La discordia entre los progenitores a la hora de trasladar a sus hijos, como primer apellido, el respectivo de cada uno de ellos suele darse cuando al inscribir el nacimiento solo se determina la maternidad (imponiendo al nacido, en consecuencia, sus apellidos), y algún (o mucho) tiempo después se determina (judicialmente, como regla general) la paternidad. La Sala Primera del Tribunal Supremo, siguiendo la senda abierta por la STC 167/2013, lleva años sentando una jurisprudencia que responde al criterio general de que el primer apellido del hijo, cuando al inscribir el nacimiento en el Registro solo se determinó la maternidad, debe mantenerse, aunque con posterioridad se determine judicialmente la paternidad. Esta solución, que comenzó a darse estando vigente la anterior legislación registral, responde al interés superior del menor, pues es beneficioso para cualquier persona mantener su identidad. Es la sentencia del Pleno 659/2016, de 10 de noviembre, la que apuntala el criterio que ya había sido aplicado por algunas sentencias en 2015, aunque podía inducir a la duda en cuanto a su ámbito de aplicación (demandas de paternidad tardías), y después ha sido mantenido en numerosas resoluciones ${ }^{48}$.

No obstante, en algunas sentencias el Tribunal Supremo parece separarse de esta doctrina, porque accede a que el apellido paterno sea el que se anteponga al materno. Pero en los casos resueltos, o bien entiende que se ha producido un acuerdo entre los progenitores (así, en la STS 638/2017, de 23 de noviembre ${ }^{49}$, que es la recurrida en amparo resuelto por la STC que ha dado pie a estas páginas) o bien considera que, a tenor de las circunstancias concurrentes, el interés del menor demanda esa solución, en lugar de mantener el primer apellido que se tuviera (así, en la STS 439/2020, de 17 de julio, que después analizaré). Expondré a continuación el supuesto general y, después, los supuestos especiales.

\section{EL INTERÉS SUPERIOR DEL MENOR RESIDE, NORMALMENTE, EN MANTENER COMO PRIMER APELLIDO EL QUE SE LE IMPUSO AL NACER}

A falta de una disposición expresa legal que ordene el mantenimiento como primer apellido de la persona el que se le impuso al nacer como conse-

48 Antes de esta fecha no encontramos en la jurisprudencia del Tribunal Supremo pronunciamientos en los que se cuestione la legalidad del art. 194 RRC (véase García Varela, 2006: 234).

49 Ponente: Excmo. Sr. D. Eduardo Baena Ruiz (RJ 2017, 5079). 
cuencia de la determinación de una única relación de filiación (la materna, normalmente), que es de lege ferenda le mejor solución, debemos confiar en el buen criterio de los tribunales de justicia para resolver las frecuentes controversias suscitadas en los casos en que se determina con posterioridad a la inscripción de nacimiento la segunda relación de filiación (normalmente la paterna $)^{50}$.

Hay que reconocerle a la Sala Primera del Tribunal Supremo su espíritu progresista al resolver los desacuerdos de los progenitores con arreglo al interés superior del menor, para superar la legalidad formalmente vigente hasta que no entró en vigor en 2017 el art. 49.2 LRC/2011 (el primer apellido del nacido, a falta de acuerdo, debe ser el paterno). En la STS 76/2015, de 17 de febrero $^{51}$, se razona que el interés superior del menor es el criterio que debe prevalecer, aunque todavía no hubiera entrado en vigor la Ley del Registro Civil de 2011. Con acierto se argumenta para estimar el recurso de casación (las Audiencias seguían resolviendo con arreglo a la Ley del Registro Civil de 1957) que la nueva ley «autoriza una interpretación correctora de la vigente, porque en los aspectos sustantivos la vigencia constitucional de los principios que la inspiran sí se encuentran [sic] en vigor».

En noviembre de 2015, el Tribunal Supremo dicta dos sentencias sucesivas en las que ya aparece su comprensión del interés superior del menor como mantenimiento del primer apellido con el que es conocida la persona desde su nacimiento (en ambos casos, al estimar el recurso de casación interpuesto por la madre cuando el hijo tiene 6 años se asume la instancia por el Tribunal Supremo y se estima el recurso de apelación —en ninguna de las dos instancias, por tanto, la pretensión de la madre había tenido éxito-). En la STS 620/2015, de 11 de noviembre ${ }^{52}$ (aunque la manera de expresar la idea es mejorable), este es el razonamiento:

50 En la propuesta de Código Civil redactada por la Asociación de Profesores de Derecho Civil, se propone una regla nueva en el art. 221-5 (dentro del Libro II, título II, sobre filiación), dedicado a los apellidos, del siguiente tenor: «El hijo mantiene como primer apellido el materno que se le haya impuesto al inscribir su nacimiento si con posterioridad queda determinada su filiación paterna».

51 Ponente: Excmo. Sr. Eduardo Baena Ruiz.

52 Ponente: Excmo. Sr. Eduardo Baena Ruiz. Del mismo ponente es la STS 621/2015, de 12 de noviembre, con argumentos que inciden más en el tiempo que pasa entre el nacimiento y la reclamación de paternidad (casi dos años) y, sobre todo, en el tiempo que lleva siendo conocido el niño con el «nomen» primigenio (en palabras de la sentencia) tanto en el ámbito familiar como en el escolar y social. 
No se trata, como afirma la sentencia de instancia, de si usar como primer apellido el del padre perjudica al menor, sino de indagar cuál será el interés superior de éste respecto de dicho extremo. Y si a la fecha que se resuelve el recurso el menor tiene cerca de seis años, durante los cuales familiar, social y escolarmente se ha identificado para el primer apellido con el de la madre, con él debe permanecer.

Pero todavía tuvo que aclarar el Tribunal Supremo la irrelevancia del escaso tiempo transcurrido entre el nacimiento y la reclamación de la paternidad, pues en la instancia se había aprovechado el resquicio dejado por las anteriores resoluciones jurisprudenciales (podía pensarse que el criterio debía seguirse cuando la reclamación de la paternidad había sido tardía) para no acoger la pretensión de la madre de conservar, como primer apellido, el materno dado que no podía sostenerse el uso social, escolar y familiar del apellido por el menor al haberse interpuesto la demanda a los pocos meses del nacimiento. Es el Pleno de la Sala de lo Civil, en su sentencia de 10 de noviembre de $2016^{53}$, el que con rotundidad enuncia la doctrina jurisprudencial que deben seguir los órganos de la instancia: si no se acredita que sea beneficioso para el menor el cambio del primer apellido que venía ostentando desde la inscripción de su nacimiento, y con el que es identificado, no hay razón para imponer el apellido paterno como primero del hijo. El padre es quien debe acreditar que el cambio del apellido será beneficioso (y esto es lo que ocurre, ya adelanto, en las resoluciones que parecen apartarse de esta doctrina general $)^{54}$.

También en la STS 645/2020, de 30 de noviembre, que estima el recurso de casación interpuesto contra la sentencia recurrida en el extremo relativo al orden de los apellidos de la menor, cuya filiación paterna se había determinado judicialmente por reclamación del sedicente progenitor (la niña había nacido en 2012 y la demanda de determinación de la filiación paterna se había interpuesto en 2015$)^{55}$.

Es ejemplo este caso, por cierto, de cómo está costando aceptar a juzgados y audiencias la doctrinal jurisprudencial sobre el orden de los apellidos en caso de determinación posterior de la paternidad, aunque se justifique la imposición del apellido paterno como primero del hijo en el interés superior del menor y

53 El ponente es, de nuevo, el Excmo. Sr. Eduardo Baena Ruiz. Comentó esta sentencia, De la Iglesia Monje (2017).

54 Esta doctrina jurisprudencial se mantiene en las SSTS 651/2017, de 29 de noviembre y 658/2017, de 1 de diciembre (RJ 2017, 5131 y 5143), en las SSTS 20/2018, de 17 de enero, 93/2018, de 20 de febrero, 130/2018, de 7 de marzo, y 266/2018, de 9 de mayo (RJ 2018, 35, 597, 786 y 1990).

55 RJ 2020, 5095. Ponente: Excmo. Sr. José Luis Seoane Spielberg. 
no en la aplicación del art. 194 RRC: reparemos en que la SAP de Sevilla recurrida en casación había declarado que se mantuviese como segundo apellido el de la madre y como primero el del padre, «lo cual no afecta de forma negativa al menor» (el Ministerio Fiscal defendió la estimación del recurso de casación). En esta sentencia, más allá de la completa exposición de la trascendencia del nombre a los efectos identificatorios de la persona y de las distintas normas y pronunciamientos, nacionales e internacionales, sobre la materia, se declara, sin cuestionamiento ninguno de su legalidad, que el art. 194 RRC estaba vigente al tiempo del nacimiento de la menor (lo que debería ser intrascendente, porque lo relevante es qué regulación estaba vigente al determinarse la paternidad), y que el interés superior del menor lo que demanda en estos casos de determinación sobrevenida de la segunda relación de filiación es la conservación del primer apellido del hijo. Otro ejemplo llamativo, todavía más reciente en el tiempo, es el de la SAP Madrid, Sección 22a de 7 de febrero de 2020, que no da ninguna explicación de por qué responde al interés del menor que cambie su primer apellido por el del progenitor que reclama con éxito su paternidad (poco después aplicará correctamente la doctrina jurisprudencial la SAP Madrid, Sección $22^{a}$, de 6 de marzo de 2020 ${ }^{56}$. El sesgo pro varón de la justicia me parece evidente. Aunque también hay ejemplos de sentencias de instancia que conservan como primer apellido el de la madre con base en que es la solución que demanda el interés superior del menor. Así, la SAP de Cantabria, Sección $2^{\mathrm{a}}$, de 22 de febrero de 2016 (FD 3), o la SAP Córdoba, Sección 1a, de 13 de marzo de $2020\left(\text { FD } 2^{\circ}\right)^{57}$.

\section{3. ¿̇CUÁNDO EL INTERÉS SUPERIOR DEL MENOR RESIDE EN QUE SE LE IMPONGA COMO PRIMER APELLIDO EL DE SU PADRE?}

En el caso de la STS 439/2020, de 17 de julio ${ }^{58}$, se reclama por el sedicente progenitor la determinación de su paternidad no matrimonial

56 AC 2020, 529 y 1385

57 Notas de prensa del Poder Judicial (consulta 16/09/2021) y JUR 2020, 190129. La sentencia del juzgado que resolvió el primer caso (la paternidad se determinó tiempo después que la maternidad pero por el juego de la presunción de paternidad matrimonial, lo que no es habitual) es un botón de muestra del automatismo de la declaración judicial de imposición del apellido paterno como primer apellido del hijo, como efecto derivado del establecimiento de la filiación paterna y consiguiente identificación del hijo con los apellidos correspondientes a su doble filiación (art. 109 CC). RJ 2020, 2503. Ponente, Excmo. Sr. Eduardo Baena Ruiz. Ha sido comentada por Del Campo Álvarez (2021), quien incide en el sentido común que impera, como tantas veces, en la toma de decisiones judiciales. 
respecto de una niña de año y medio de edad, impugnando a la vez la paternidad matrimonial que consta inscrita en el Registro Civil. En su demanda, presentada en 2017 (por tanto, cuando ya había desaparecido toda preferencia legal a favor del apellido paterno), el actor solicita también que se rectifiquen los apellidos de la niña para que el suyo conste como primero de los de su hija, una vez declarada la paternidad no matrimonial. La parte demandada solo se opuso a esta petición sobre cuál debía ser el primer apellido de la niña, defendiendo que fuera el materno ${ }^{59}$. Debe señalarse, como hecho distintivo de este caso, que cuando se inscribió la filiación matrimonial de la niña, como primer apellido se le impuso el de su padre (cuya filiación se impugnó con éxito en el proceso, decayendo en consecuencia todos sus efectos), y como segundo apellido el de su madre. El interés superior de la menor es el criterio que se tiene en cuenta por los órganos judiciales para decidir la controversia, pero es el Tribunal Supremo el que acierta en la comprensión de cuál sea este mejor interés en el caso: la niña tiene hermanos por parte de padre y por parte de madre, y si se impone el apellido materno como primero, su primer apellido será distinto del de todos sus hermanos; en cambio, si se le impone como primer apellido el del padre, los compartirá con sus hermanos por parte de padre.

En cambio, no se ha considerado que deba imponerse el apellido paterno como primero de los de la hija no matrimonial porque de ese modo compartiría apellido con su hermana, hija matrimonial del padre, pues no es suficiente beneficio que permita inclinar la balanza del interés superior del menor, por la STS 130/2018, de 7 de marzo (RJ 2018, 786; ponente: Excmo. Sr. Eduardo Baena Ruiz).

¿Y cuál sería la mejor solución si se le ha impuesto al hijo, como primer apellido, el segundo de la madre, lo que permitía y permite la legislación registral, y después se determina la paternidad? ¿Podría tener éxito la pretensión de la madre de que el segundo apellido del hijo pasase a ser primero y el del padre fuera segundo de los del hijo? Sí, aplicando con rigor la legalidad, como hizo la SAP Madrid, Sección 22a, de 24 de mayo de 2021 (JUR 2021, 274894), en un caso en que la pretensión de la madre era, por el contrario,

59 Es interesante, por cierto, este caso en cuanto a la legitimación pasiva, pues la madre, en su nombre y como representante de su hija, es la única demandada que podría oponerse a la solicitud relativa al orden de los apellidos que tendría la niña una vez determinada la paternidad no matrimonial. Si triunfa la acción mixta de reclamación-impugnación de la filiación (art. 134 CC), ningún interés puede tener quien ya ha dejado de ser considerado padre. 
que se mantuviera como primer apellido el que ya ostentaba su hijo, que era el segundo materno.

Por último, debemos tener en cuenta que el menor con suficientes condiciones de madurez, al que debe oírse en el juicio sobre determinación de su paternidad respecto de las peticiones de los progenitores sobre el orden de sus apellidos (art. 9 LOPJM), puede mostrar su preferencia por el apellido paterno ${ }^{60}$. El caso, muy interesante, ya se ha dado en la práctica, aunque la SAP Madrid, Sección 24a , de 9 de marzo de 2021 (JUR 2021, 179191) desestimó el recurso de apelación de la madre, que había acordado con el padre mantener como primer apellido de su hijo de 14 años el materno, razonando que el interés superior del menor no venía al caso ante la existencia de acuerdo. El hijo prefería ostentar el apellido paterno.

\section{COMENTARIO CRÍTICO DE LA STC 178/2020, DE 14 DE DICIEMBRE}

Concluyo este trabajo volviendo a la sentencia que motivó esta investigación $^{61}$. El Tribunal Supremo desestimó el recurso de casación interpuesto

60 Un interesante pronunciamiento sobre cuándo deben ser escuchados los menores en los procesos de familia y menores se contiene en la STS 577/2021, de 27 de julio (RJ 2021, 4023; ponente: Excmo. Sr. Antonio García Martínez).

61 La historia judicial había comenzado, por lo que respecta al único tema verdaderamente controvertido (el orden en que debían imponerse a la hija los respectivos primeros apellidos de la madre y del padre), con la petición de la actora, en su demanda, de que, declarada la paternidad reclamada, el primer apellido de su hija fuera el paterno y el segundo apellido el materno; el demandado, por su parte, se mostró conforme con someterse a la prueba biológica de paternidad y pidió que se estimaran o desestimaran las peticiones de la demandante dependiendo del resultado de la prueba. En el acto de la vista, celebrada el 18 de febrero de 2014, la demandante varió la petición referente al orden de los apellidos, instando que primero fuera el materno y segundo el paterno; petición a la que se opuso el demandado por considerarla extemporánea. El juzgado estimó la demanda y fijó como apellidos los solicitados por la madre en el acto de la vista; el demandado intentó, sin éxito, la aclaración de la sentencia, por entender que el cambio del orden de los apellidos resultante de la demanda y la contestación le había causado indefensión además de no estar suficientemente motivado (art. $24 \mathrm{CE}$ ), y reiteraba la aplicabilidad del criterio alfabético para resolver la falta de acuerdo de los progenitores manifestada en el acto de la vista. El recurso de apelación interpuesto por el demandado, al que se adhirió el Ministerio Fiscal, fue estimado porque, a juicio de la audiencia, el juzgado había incumplido el 
por la madre ${ }^{62}$ apoyándose en los siguientes razonamientos: i) el cambio de petición de la madre sobre el orden de los apellidos fue sorpresiva, más que extemporánea; ii) la demanda y su contestación tienen un efecto preclusivo en la configuración de la litis; iii) la sentencia del juzgado adolecía de una falta de motivación; iv) no se ha vulnerado el interés superior de la menor porque no había que considerarlo, dado el acuerdo entre las partes respecto al orden de los apellidos en caso de declararse la filiación paterna, y además la prevalencia de este interés solo se suscitó en el recurso de casación, con clara indefensión para la parte recurrida. Esta sentencia permitió que se rectificasen en el Registro Civil los apellidos de la menor el 12 de enero de 2018, lo que se tuvo en cuenta por el Tribunal Constitucional para desestimar la pretensión de la recurrente de suspender la ejecución de su fallo, pues se estaría anticipando entonces el amparo (ATC 55/2019, de 3 de junio).

deber de motivación, la petición de permanencia del apellido materno como primero de la niña fue introducida extemporáneamente en el proceso, y por último la decisión no se ajustaba a la legalidad vigente (arts. 109 y 111 CC, y arts. 194 y 196 RRC). Es interesante incidir en el papel que el Ministerio Fiscal está interpretando en los procesos sobre orden de los apellidos, pues no apreciamos una línea de actuación uniforme. En este caso y momento procesal, el fiscal defiende que debía figurar el apellido del padre en primer lugar porque la demandante no había acreditado que el cambio de apellidos pudiere afectar a la menor de alguna manera (véase antecedente 2.f) STC 178/2020, de 14 de diciembre). En cambio, ante el Tribunal Supremo, en el mismo caso, el fiscal defiende que el primer apellido sea el materno, pues es lo que demanda el interés superior del menor, interés que debe conseguirse aun a costa de un menor rigor formal y la exclusión de la preclusión de los actos procesales (véase antecedente 2.j) STC 178/2020). Ante el Tribunal Constitucional, el fiscal también defiende con argumentos sólidos el mantenimiento como primer apellido del materno (antecedente 10 STC 178/2020).

62 Ante la Audiencia, no esgrimió el interés superior de la menor como criterio determinante del mantenimiento como primer apellido del materno, sino el argumento (confuso) de que solo la madre podía solicitar el cambio en el orden de los apellidos, no el padre hasta que no fuera reconocido como tal por sentencia firme, y que no era necesaria la motivación del cambio porque solo ella estaba legitimada (véase antecedente 2.f) STC 178/2020, de 14 de diciembre). Mejor asesorada, en el recurso de casación sí invoca el interés superior del menor y el art. 39 CE para que se mantenga como primer apellido el materno, además del abuso de derecho en que incurre el varón que no reconoce voluntariamente su paternidad, aun conociendo el embarazo y nacimiento de la niña, ni se preocupa, en consecuencia, por el tema de los apellidos hasta que no se interpone la demanda de determinación de su paternidad (véase antecedente 2.g) STC 178/2020). 
Acierta el Tribunal Constitucional cuando justifica la exclusión de la preclusión procesal en un proceso como el de marras, aunque habría que insistir en el respeto del derecho de defensa de las partes, y desde luego es cierto todo el valor que tiene el principio constitucional del interés superior del menor (art. 39.4 CE) ${ }^{63}$. Pero son más endebles sus razones para entender que se ha vulnerado el derecho a la tutela judicial efectiva de la madre-demandante porque no se ha atendido al interés superior del menor en la decisión relativa a los apellidos que debía llevar a partir del momento en que queda determinada la paternidad. Imputa al Tribunal Supremo una vulneración que, en mi opinión, no existe: en la sentencia recurrida en casación, sí se motiva por qué no hay que atender al interés superior del menor, y es una motivación suficiente y nada irracional. Razona el Tribunal Supremo, quizás no con la rotundidad y propiedad necesarias, que el criterio del interés superior del menor entra en escena en defecto de acuerdo entre los progenitores, acuerdo que en el caso cabe hallar en la conformidad de la demandada con la petición del demandante, teniendo como tiene, además, efecto preclusivo de la litis tal acuerdo $^{64}$. Ya no hay marcha atrás, viene a decir el Supremo, y es verdad que no hay razón para permitir que cambie de opinión alguno de los progenitores. Cuestión distinta es (lo que no se plantean Tribunal Supremo ni Tribunal Constitucional) que podamos entender la actuación de la madre, al mostrar su conformidad con que cambie el primer apellido de su hija cuando se determine la paternidad, respetuosa con el interés superior de esta, dado que el derecho al nombre, como derecho de la personalidad, justifica mantener ese primer apellido que ya se ostenta desde el nacimiento.

El Tribunal Supremo, además, se apoyó en la STC 242/2015, de 30 de noviembre, que no había admitido el recurso de amparo interpuesto en un caso en que la madre no se había opuesto en la contestación a la demanda de reclamación de la paternidad ejercida por el sedicente progenitor a que el primer apellido fuera el de este, una vez determinada la paternidad (petición expresa sobre apellidos del actor), pero sí lo había hecho en el acto de la vista, solicitando que se mantuviera el primer apellido (materno) que ya tenía la

63 Salas Carceller (2021) resume con precisión el caso y la sentencia, y concluye afirmando que, aunque el interés del menor permite justificar una actuación de oficio de los órganos judiciales, la modificación de las peticiones formuladas en la demanda, una vez contestada a misma, «impide efectivamente al demandado ejercer su derecho a una oposición adecuada, difícil de articular cuando se plantea posteriormente en el acto del juicio».

64 Induce a confusión que primero razone esto el Tribunal Supremo, y después sostenga que como el interés superior del menor no se ha invocado en la instancia, causaría indefensión al demandante entrar a conocer del tema en casación. 
menor. Y parece razonable que el Tribunal Supremo considerase que el mismo efecto preclusivo se diera ahora, pues en definitiva ambos escritos son actos procesales en los que las partes fijan sus pretensiones.

\section{CÓMO AVANZAR PARA CONSEGUIR UNA EFECTIVA IGUALDAD POR RAZÓN DE SEXO EN LA IMPOSICIÓN DE APELLIDOS}

En mi opinión, la auténtica igualdad de trato entre hombres y mujeres no se consigue únicamente dando entrada a la autonomía privada en la elección de los apellidos y resolviendo los desacuerdos con el interés superior del menor, que como criterio subsidiario ha introducido una complejidad, y aleatoriedad, en la imposición de los apellidos muy desaconsejable dada la premura en que conviene identificar de manera estable a las personas ${ }^{65}$. Pero, a decir verdad, ¿hay algún criterio aceptable?66

El principio de no discriminación por razón de sexo se traduce, formalmente, en que no cabe preferir el apellido paterno sobre el materno por el solo hecho de que es el del padre. Y, parece, tampoco podría preferirse el materno por el solo hecho de que es el de la madre. Pero como socialmente la preferencia del paterno no ha sido todavía superada, porque un acuerdo consciente y deliberado entre los progenitores no es habitual, ¿habría que poner las piedras necesarias para conseguir una plena vigencia del principio de no discriminación? ¿Puede defenderse, como medida de discriminación positiva, la elección del apellido materno como primero de los del hijo en caso

65 Torrelles Torrea (2016: 199, 201) argumenta bien la necesidad de que el criterio subsidiario sea lo más automático posible, y es partidaria de sortear el orden de los apellidos. Afirmaciones atinadas sobre la inutilidad de un criterio como el interés superior del menor al inscribir el nacimiento en Serrano-Fernández (2001: 723). Incide en la inevitable aleatoriedad si no se prefiere ninguno de los apellidos, Navarro Castro (2012: 730).

66 En la tramitación parlamentaria de la LRC/2011 aparecieron distintos criterios (los repasa Torrelles Torrea, 2016: 196-197), más o menos peregrinos, para evitar recurrir a un concepto tan poco apropiado, en esta materia de imposición de apellidos, como el del interés superior del menor (como regla general). Anteponer el apellido menos frecuente o el que estuviera en mayor riesgo de desaparecer (criterios, en principio, sensatos); seguir el orden alfabético (criterio seguido, por cierto, por el legislador galo al reformar en 2021 su regulación); recurrir al azar y sortear el orden (salomónico); hacer prevalecer el apellido del progenitor de más edad (hipócrita si lo buscado es garantizar la igualdad de trato); imponer el apellido paterno a los niños y el materno a las niñas... (sin más, una ocurrencia). 
de falta de acuerdo entre los progenitores? A su favor militaría la sencillez de la opción legislativa basada en el principio mater semper certa est. Y de la STEDH de 26 de octubre de 2021 (caso León Madrid contra España) puede desprenderse que una norma que dé preferencia al apellido materno, conforme con el principio de seguridad jurídica, no es en todo caso discriminatoria: solo lo sería si se aplicase automáticamente sin atender a las circunstancias del caso (vid. los parágrafos 68 y 69).

\section{Bibliografía}

Álvarez González, S. y García Rubio, M. P. (2013). El nombre de las personas físicas. En M. C. Gete-Alonso y Calera (dir.) y J. Solé Resina (coord.). Tratado de derecho de la persona fisica, Tomo I (pp. 469-521). Cizur Menor: Civitas Thomson Reuters.

Artacho Martín-Lagos, M. (2018). La determinación judicial del orden de los apellidos: discriminación por razón de sexo, interés superior del menor y violencia de género. Práctica de Tribunales: Revista de Derecho Procesal Civily Mercantil, 130, 6.

Barber Cárcamo, R. (2010). Apellidos y Registro Civil. Actualidad Jurídica Aranzadi, $809,579-587$.

Bengoechea, M. (2006). La subordinación simbólica como fuente de violencia: el lenguaje como vehículo de discriminación contra las mujeres. II Congreso sobre violencia doméstica y de género (Granada, 23 y 24 de febrero de 2006).

Bercovitz Rodríguez-Cano, R. (2014). El nombre y los apellidos. Revista Doctrinal Aranzadi Civil-Mercantil, 9, 37-40.

Berrocal Lanzarot, A. I. (2017). La identidad personal. El nombre y los apellidos. El interés superior del menor. Revista Crítica de Derecho Inmobiliario, 760, 937-975.

Cicero, C. (2018). Il diritto al cognome materno. Diritto di Famiglia e delle Persone, $1,245-258$.

Corera Izu, M. (2018). El nombre y los apellidos en la «nueva» ley registral. Revista Aranzadi Doctrinal, 3, 229-245.

De Angelis, M. (2021). L'automatica attribuzione del cognome paterno al vaglio della Consulta. Il Diritto della Familia e delle Succesioni in Europa.

De la Iglesia Monje, M. I. (2017). El interés superior del menor y el orden de los apellidos sin acuerdo de los progenitores tras la determinación de la filiación de manera sobrevenida. Revista Crítica de Derecho Inmobiliario, 93 (761), 1433-1448.

Del Campo Álvarez, B. (2021). Cambio de paternidad y orden de apellidos ante la existencia de hermanos. Comentario a la STS 439/2020 de 17 de julio (RJ 2020, 2503). Cuadernos Civitas de Jurisprudencia Civil, 937, 245-250.

Egusquiza Balmaseda, M. A. (2005). Derecho al apellido: tradición, igualdad y ciudadanía europea (A propósito de la STEDH de 16 de noviembre de 2004, asunto Ünal Tekeli). Repertorio Aranzadi del Tribunal Constitucional, 11, 13-31.

García Varela, R. (2006). Artículo 109. En I. Sierra Gil de la Cuesta (coord.). Comentario del Código Civil (vol. 2). Barcelona: Bosch. 
Linacero de la Fuente, M. (2012). El estado civil y el principio de igualdad en el orden de transmisión de los apellidos en la nueva Ley del Registro Civil. Diario La Ley, 7885.

- (2013). Tratado del Registro Civil. Adaptado a la Ley 20/2011, de 21 de julio, del Registro Civil. Valencia: Tirant lo Blanch.

Minero Alejandre, G. (2020). Estudio sobre la regulación del cambio de apellidos de la persona víctima de violencia de género y/o sus descendientes. En A. Valiño Ces y A. Rodríguez Álvarez (coords.), R. Castillejo Manzanares y C. Alonso Salgado (dirs.). El género y el sistema de (in)justicia (pp. 523-530). Valencia: Tirant lo Blanch.

Navarro Castro, M. (2012). Comentario al artículo 49. En. J. A. Cobacho Gómez y A. Liceñena Ibarra (coords.). Comentarios a la Ley de Registro Civil. Cizur Menor (Navarra):Thomson Reuters Aranzadi.

Ordás Alonso, M. (2014). Imposición al menor del apellido paterno: igualdad, derecho a la propia imagen, interés del menor. Derecho Privado y Constitución, 28, 47-92.

Quicios Molina, M. S. (2021). Artículo 109. En R. Bercovitz (coord.). Comentarios al Código Civil. Cizur Menor (Navarra): Thomson Reuters Aranzadi.

Rivero Hernández, F. (1993). Artículo 109. En C. Paz-Ares, R. Bercovitz, L. Díez-Picazo y P. Salvador (dirs.). Comentario del Código Civil. Tomo I. Madrid: Ministerio de Justicia.

Romero Coloma, A. M. (2013). El derecho al nombre y los apellidos como derecho fundamental de la persona. Revista Jurídica del Notariado, 85, 97-110.

Ruiz-Rico Ruiz, J. M. (2020). Los efectos de la determinación de la filiación: ‘automaticidad o supervisión previa? Revista de Derecho de Familia, 86, 33-87.

Salas Carceller, A. (2021). El interés del menor y el orden de los apellidos. Sentencia del Tribunal Constitucional de 14 diciembre 2020, Rec. Amparo 6318/2017. Revista Aranzadi Doctrinal, 2, 174.

Salvador Gutiérrez, S. (1997). Artículo 194. En R. Bercovitz (coord.). Comentarios al Código Civil. Tomo IV (vol. 5). Artículos 165 al final del Reglamento de la Ley del Registro Civil. Boadilla del Monte: Edersa.

- (2005). Artículo 53. Artículo 55. En R. Bercovitz (coord.). Comentarios al Código Civil. Tomo IV (vol. 3). Artículos 40 al final de la Ley del Registro Civil. Boadilla del Monte: Edersa.

Serrano-Fernández, M. (2001). Régimen jurídico del nombre y los apellidos en el Derecho español. Revista de Derecho Privado, 687-733.

Torrelles Torrea, E. (2016). La elección del orden en los apellidos por parte de los progenitores y los criterios de determinación a falta de acuerdo en la Ley de Registro Civil 2011. Revista Critica de Derecho Inmobiliario, 753, 185-222.

Vela Sánchez, A. J. (2020). Violencia de género sobre la pareja y derecho a cambiar el nombre y los apellidos. Diario La Ley, 9720.

Verdera Server, R. (2013). Artículo 109. En R. Bercovitz (dir.). Comentarios al Código Civil. Tomo I. Valencia: Tirant lo Blanch. 